\title{
Nonlinear behaviour of conduction and block in cardiac tissue with heterogeneous expression of connexin 43
}

\section{Yann Prudat and Jan P. Kucera}

Department of Physiology, University of Bern, Bühlplatz 5, CH-3012 Bern, Switzerland

Yann Prudat $\quad$ yann.prudat@gmail.com

Jan P. Kucera kncera@pyl.unibe.ch

\section{Accepted Author Manuscript}

NOTICE: This is the author's version of a work that was accepted for publication in Journal of Molecular and Cellular Cardiology. Changes resulting from the publishing process, such as peer review, editing, corrections, structural formatting, and other quality control mechanisms may not be reflected in this document. Changes may have been made to this work since it was submitted for publication. A definitive version was subsequently published in Journal of Molecular and Cellular Cardiology, 2014, 76:46-54.

DOI: $10.1016 /$ j.yjmcc.2014.07.019

Highlights:

Conduction was studied in tissue formed by cells expressing different connexin levels Experiments were paralleled with simulations using a detailed tissue structure model Conduction in heterogeneously uncoupled tissue is slow and highly prone to block Conduction in heterogeneous tissue is more sensitive to changes in ion currents Tissue with heterogeneous connexin expression is a highly arrhythmogenic substrate

Corresponding author:

Jan P. Kucera

Department of Physiology

University of Bern

Bühlplatz 5

CH-3012 Bern

Switzerland

Phone: $\quad$ +41316318759

Fax: $\quad$ +41316314611

E-mail: kucera@pyl.unibe.ch 


\begin{abstract}
Altered gap junctional coupling potentiates slow conduction and arrhythmias. To better understand how heterogeneous connexin expression affects conduction at the cellular scale, we investigated conduction in tissue consisting of two cardiomyocyte populations expressing different connexin levels. Conduction was mapped using microelectrode arrays in cultured strands of foetal murine ventricular myocytes with predefined contents of connexin 43 knockout (Cx43KO) cells. Corresponding computer simulations were run in randomly generated two-dimensional tissues mimicking the cellular architecture of the strands. In the cultures, the relationship between conduction velocity (CV) and $\mathrm{Cx} 43 \mathrm{KO}$ cell content was nonlinear. CV first decreased significantly when Cx43KO content was increased from 0 to $50 \%$. When the $\mathrm{Cx} 43 \mathrm{KO}$ content was $\geq 60 \%, \mathrm{CV}$ became comparable to that in $100 \% \mathrm{Cx} 43 \mathrm{KO}$ strands. Co-culturing $\mathrm{Cx} 43 \mathrm{KO}$ and wild-type cells also resulted in significantly more heterogeneous conduction patterns and in frequent conduction blocks. The simulations replicated this behaviour of conduction. For Cx43KO contents of 10-50\%, conduction was slowed due to wavefront meandering between $\mathrm{Cx} 43 \mathrm{KO}$ cells. For Cx43KO contents $\geq 60 \%$, clusters of remaining wild-type cells acted as electrical loads that impaired conduction. For Cx43KO contents of 40-60\%, conduction exhibited fractal characteristics, was prone to block, and was more sensitive to changes in ion currents compared to homogeneous tissue. In conclusion, conduction velocity and stability behave in a nonlinear manner when cardiomyocytes expressing different connexin amounts are combined. This behaviour results from heterogeneous current-to-load relationships at the cellular level. Such behaviour is likely to be arrhythmogenic in various clinical contexts in which gap junctional coupling is heterogeneous.
\end{abstract}

\title{
Keywords
}

connexin 43; cardiac cell cultures; microelectrode arrays; computer model; conduction velocity; conduction block.
Abbreviations
Cx43 connexin 43
Cx43KO connexin 43 knockout
WT wild-type
CV conduction velocity
CvarCT $_{d} \quad$ coefficient of variation of conduction time sampled over segments of length $d$
EAT earliest activation time
$\mathrm{dV} / \mathrm{dt}_{\max } \quad$ maximal rate of rise of transmembrane potential
UDB unidirectional conduction block 


\section{Introduction}

Action potential propagation is crucial for cardiac function. Conduction disorders can lead to arrhythmias, which are frequent complications of heart disease [1]. The velocity and safety of cardiac conduction depend on multiple factors. Direct factors include inward ion currents [1,2], gap junctional coupling [2-6] and tissue architecture [7,8]. Indirect factors include interactions between myocytes and stromal cells $[9,10]$ and outward $\mathrm{K}^{+}$currents (in particular the inward rectifier $\mathrm{K}^{+}$ current [11]), which determine the resting membrane potential and resistance, and thus the availability of the inward $\mathrm{Na}^{+}$current.

Ventricular myocytes are connected electrically by gap junctional channels formed principally by connexin 43 (Cx43) and, to a smaller extent, connexin 45 [12]. Cx43 knockout (Cx43KO) mice thus represent a model to investigate the primeval role of $\mathrm{Cx} 43$ in ventricular conduction. In embryonic mice, the homozygous $\mathrm{Cx} 43 \mathrm{KO}$ mutation slowed ventricular conduction by $80 \%$ [4]. In cultures of murine ventricular Cx43KO myocytes, conduction was even slowed by $96 \%$ and it was supported by a low level of connexin 45 expression [5].

However, a spatially irregular pattern of Cx43 expression may also be arrhythmogenic. Heterogeneous connexin expression occurs, e.g., in dilated cardiomyopathy [13], heart failure [14], ischemia [15] and infarction [16,17]. These conditions result in a very variable loss of Cx43 expression in ventricular tissue, which potentiates arrhythmias. Heterogeneous coupling could also occur during cardiac cellular therapies if transplanted cells do not connect sufficiently with recipient tissue. This situation may also pertain to the genetic mosaicism of a loss-of-function Cx43 mutation identified in the atrial tissue of a patient with lone atrial fibrillation [18]. In optical mapping studies, this scenario was investigated in ventricles of chimeric $\mathrm{Cx} 43 \mathrm{KO}$ mice, consisting of macroscopic patches of Cx43KO myocardium mingled with wild-type (WT) tissue. Conduction exhibited localized conduction defects and these hearts were prone to re-entrant arrhythmias [19]. However, in another study with cultured strands of mixed Cx43KO and WT cells [6], no conduction blocks were reported. Furthermore, conduction velocity (CV) decreased linearly with the proportion of $\mathrm{Cx} 43 \mathrm{KO}$ cells, an unexpected fact because the relationship between CV and coupling is typically nonlinear $[2,20]$.

To obtain clearer insights into conduction in tissue consisting of myocytes expressing different connexin levels, we mapped propagation in such strands of mixed cells over macroscopic lengths using microelectrode arrays and conducted simulations using a tissue model permitting to define specific tissue architectures at subcellular resolution. In contrast with previous findings [6], we observed in both experiments and simulations a clearly nonlinear relationship between CV and Cx43KO cell content. Importantly, we found that conduction became not only very heterogeneous but also prone to block in the co-cultures. At the cellular scale, this behaviour resulted from fluctuations of the balance between the depolarizing current generated by the wavefront and the electrical load represented by the adjacent tissue downstream. Conduction blocked when the mismatch between the generated current and the electrical load (current-to-load mismatch [1]) became too important. In simulations, we also observed that conduction in heterogeneous strands was more sensitive to changes in ion currents. Finally, we observed that activation patterns in such tissues exhibit fractal characteristics. Altogether, these results indicate that heterogeneous connexin expression at the cellular level is prominently arrhythmogenic. 


\section{Materials and Methods}

Methods are presented in detail in the supplementary material.

\subsection{Electrophysiological experiments}

Strands (150-200 $\mu \mathrm{m}$ wide) of foetal murine ventricular myocytes containing predefined proportions of WT and Cx43KO cells were cultured on microelectrode arrays over rows of 12 recording electrodes (spacing: $0.5 \mathrm{~mm}$ ). Extracellular unipolar electrograms were recorded during pacing at a cycle length of $300 \mathrm{~ms}$.

CV was determined by linear regression of activation times. Conduction heterogeneity was quantified as the coefficient of variation (Cvar, ratio of standard deviation to mean) of conduction time (CT) between adjacent recording sites (CvarCT $\mathrm{d}_{\mathrm{d}}$, with $d=0.5 \mathrm{~mm}$ being the electrode spacing).

\subsection{Computer simulations}

Corresponding simulations of conduction were run in two dimensional strands ( $3 \mathrm{~mm}$ long, 150 or $60 \mu \mathrm{m}$ wide) mimicking cardiac cellular architecture, with a random distribution of WT/Cx43KO genotypes. Membrane currents were simulated using a modified Luo-Rudy phase 1 (LR1) model [21] with enhanced $\mathrm{Ca}^{2+}$ current.

Activation was monitored by identifying the earliest activation time (EAT) at every coordinate $x$ along the strand. CV was computed by linear regression of EAT vs. $x$ over $25-75 \%$ of strand length. As in experiments, conduction heterogeneity was evaluated by sampling EAT at points separated by $d=0.5 \mathrm{~mm}$ and by computing CvarCT $_{\mathrm{d}}$. To ascertain the presence of fractal activation patterns, the power-law dependence of $\mathrm{CvarCT}_{\mathrm{d}}$ on $d$ was identified by examining $\mathrm{CvarCT}_{\mathrm{d}}$ vs. $d$ in double logarithmic plots and by estimating the Hurst exponent (a measure of self-similarity [22]) of EAT $(x)$.

\subsection{Statistics}

Unless specified otherwise, data are presented as means \pm standard deviations. Differences between means were evaluated using ANOVA at a significance level of $p<0.05$. To compare the probabilities of conduction success or block, 95\% confidence intervals were computed using the Clopper-Pearson exact method.

\section{Results}

\subsection{Conduction characteristics in cultured strands with predefined $\mathrm{Cx} 43 \mathrm{KO}$ cell contents}

Figure 1 shows representative recordings in cultured strands with predefined Cx43KO cell contents. In the 100\% WT strand (Figure 1A), conduction was rapid $(44.2 \mathrm{~cm} / \mathrm{s})$, with regular intervals between successive electrograms $\left(\right.$ CvarCT $\left._{0.5 \mathrm{~mm}}=0.07\right)$. The signals exhibited a spatially uniform typical biphasic shape. In the $100 \%$ Cx43KO strand (Figure 1B), conduction was very slow $(2.47 \mathrm{~cm} / \mathrm{s})$ and the electrogram amplitude was several times smaller compared to the $100 \% \mathrm{WT}$ strand. This smaller amplitude can be explained by a narrower wavefront due to slow conduction and thus a smaller number of cells contributing to the extracellular potential. To compare signal morphologies, 10 successive electrograms were averaged on the right of Figure $1 \mathrm{~B}$. This analysis reveals the irregular and multiphasic shapes of the signals. Despite this heterogeneous signal morphology, propagation appeared uniform $\left(\right.$ CvarCT $\left._{0.5 \mathrm{~mm}}=0.12\right)$. In the $30 \% \mathrm{Cx} 43 \mathrm{KO}$ cell strand (Figure 1C), overall CV was $17.6 \mathrm{~cm} / \mathrm{s}$. The signal morphology was irregular (no averaging in Figure $1 C)$ and conduction was highly heterogeneous $\left(\right.$ CvarCT $\left._{0.5 \mathrm{~mm}}=0.87\right)$. In the $70 \% \mathrm{Cx} 43 \mathrm{KO}$ strand (Figure 1D), CV $(2.74 \mathrm{~cm} / \mathrm{s})$ was comparable to that in the $100 \% \mathrm{Cx} 43 \mathrm{KO}$ strand despite the 
presence of $30 \%$ of WT cells. The electrograms were irregular and conduction was more heterogeneous ( $\mathrm{CvarCT}_{0.5 \mathrm{~mm}}=0.23$ ) than in monogenotypic preparations.

Conduction block (full or intermittent) was observed in some strands combining WT and Cx43KO cells, as illustrated for a Cx43KO content of 50\% in Figures 1E (preparation without block) and $1 \mathrm{~F}$ (preparation with block).
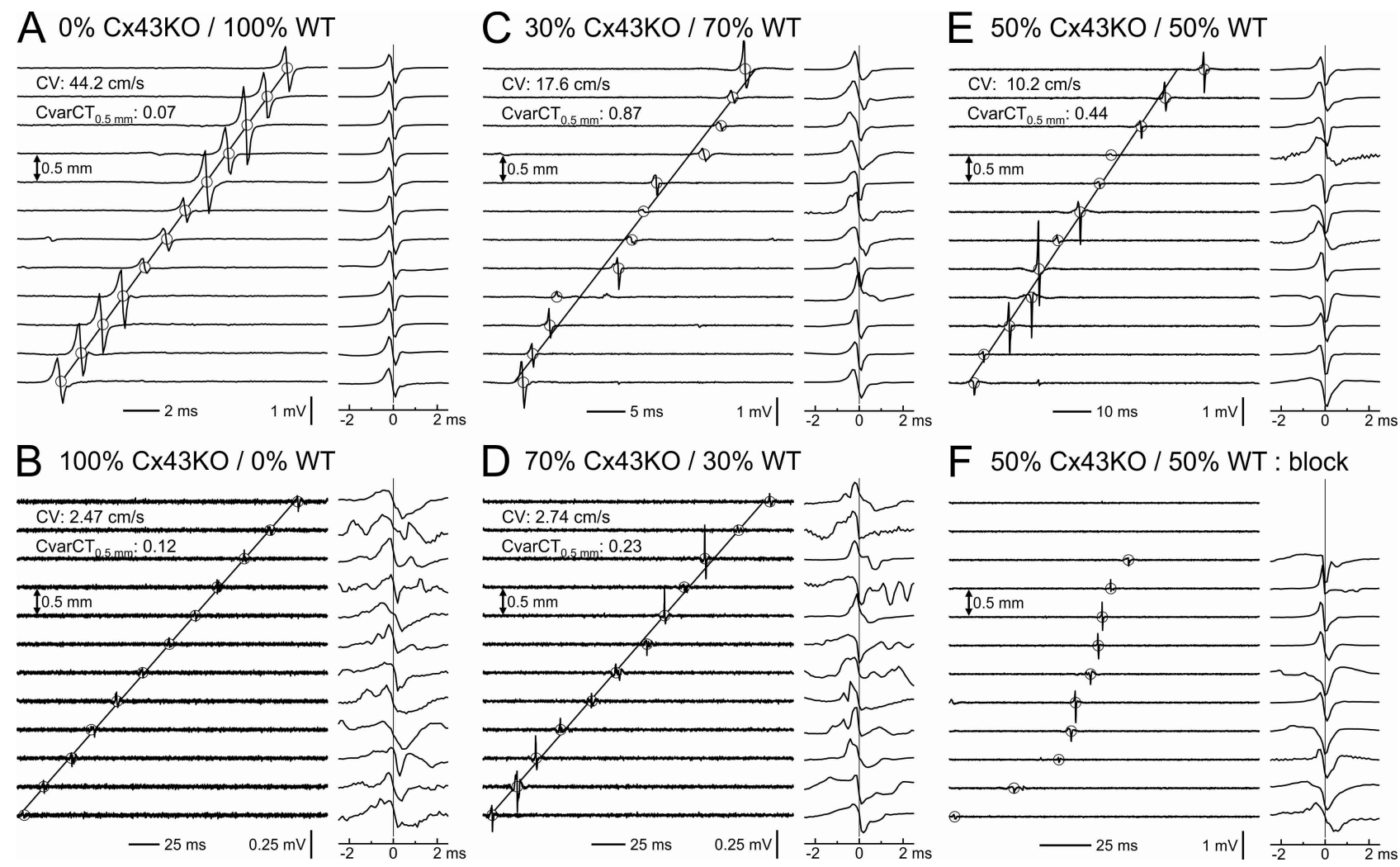

F $50 \%$ Cx43KO / 50\% WT : block

Figure 1. Electrograms recorded in cultured strands with predefined $\mathrm{Cx} 43 \mathrm{KO}$ cell contents. (A) $0 \%$ Cx43KO (100\% WT); (B) 100\% Cx43KO; (C) 30\% Cx43KO; (D) 70\% Cx43KO; (E) 50\% Cx43KO; (F) $50 \%$ Cx43KO, with conduction block. Oblique lines represent linear fits of activation times (marked by circles). On the right of each panel, electrograms are aligned and normalized to have the same amplitude (averages of 10 successive electrograms are shown in B and D).

The systematic analyses of $\mathrm{CV}$ and $\mathrm{CvarCT}_{0.5 \mathrm{~mm}}$ as a function of the $\mathrm{Cx} 43 \mathrm{KO}$ cell content as well as the proportions of preparations exhibiting block are presented in Figure 2. The relationship between $\mathrm{CV}$ and $\mathrm{Cx} 43 \mathrm{KO}$ content was globally nonlinear. $\mathrm{CV}$ decreased gradually when the Cx43KO content was increased from 0 to $50 \%$ and reached the lowest level at Cx43KO contents $\geq 60 \%$. In contrast to the monotonic decrease of $\mathrm{CV}, \mathrm{CvarCT}_{0.5 \mathrm{~mm}}$ exhibited a biphasic behaviour: it was the lowest for monogenotypic preparations and higher in strands where the genotypes were mixed. Thus, conduction velocity and heterogeneity depended in a nonlinear manner on the Cx43KO cell content. Conduction was susceptible to block in preparations with mixed WT and Cx43KO cells, while block was never observed in monogenotypic preparations. 


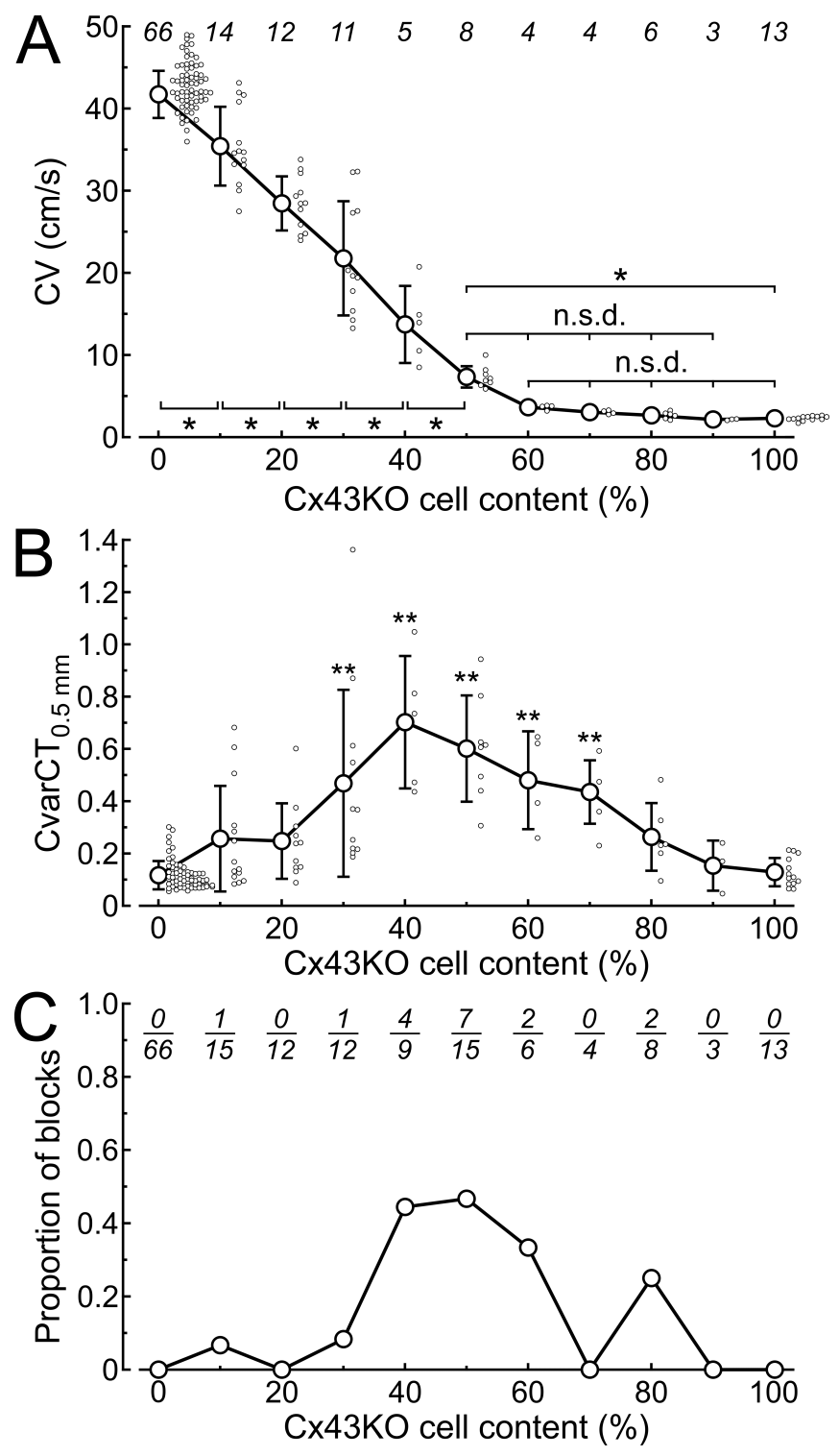

Figure 2. Conduction characteristics vs. Cx43KO cell content in cultured strands. (A) CV and number of individual preparations. *: $\mathrm{p}<0.05$. n.s.d.: not significantly different from each other. $(B)$ CvarCT $_{0.5 \mathrm{~mm}}{ }^{* *}: \mathrm{p}<0.05$ vs. both $0 \%$ and $100 \%$ Cx43KO. In A and B, individual data points are shown as small circles shifted to the right. (C) Proportion of strands exhibiting block (ratios above the plot). These preparations were not included in the analyses shown in A and B.

\subsection{Conduction characteristics in simulations with detailed tissue architecture}

To further explore the spatiotemporal excitation patterns resulting from the association of normal and poorly coupling cardiomyocytes, we conducted simulations of conduction in computer-generated strands incorporating the cellular detail of tissue architecture and genotype.

Figure 3 and Video 1 illustrate propagation in a strand with 30\% Cx43KO cells. The random distribution of cellular genotypes resulted in clusters of poorly coupled $\mathrm{Cx} 43 \mathrm{KO}$ cells that disrupted the tissue and that formed barriers which substantially delayed excitation or diverted the wavefront. Excitation meandered through the remaining WT tissue. The random distribution of WT/Cx43KO 
cells even occasionally resulted in groups of cells that were activated in a retrograde manner (indicated by an arrow in the rightmost third of the activation map in Figure 3A). Isolated Cx43KO cells were activated 1-2 ms after the passage of the main wavefront. Furthermore, there was a manifest dispersion of activation time in the transverse direction (Figure 3B). Thus, propagation was very heterogeneous, reminiscent of the "zig-zag" conduction described previously in infarct scars [8]. On the one hand, the delayed activation of Cx43KO cells and the absence of any electrical load on these cells during their excitation resulted, on average, in large $\mathrm{dV} / \mathrm{dt}_{\max }$ compared to WT cells. On the other hand, fluctuations of the current-to-load relationship during wavefront meandering resulted in enormous $\mathrm{dV} / \mathrm{dt}_{\max }$ variations in WT cells. Heterogeneous activation resulted in simulated electrograms with irregular and multiphasic waveforms.

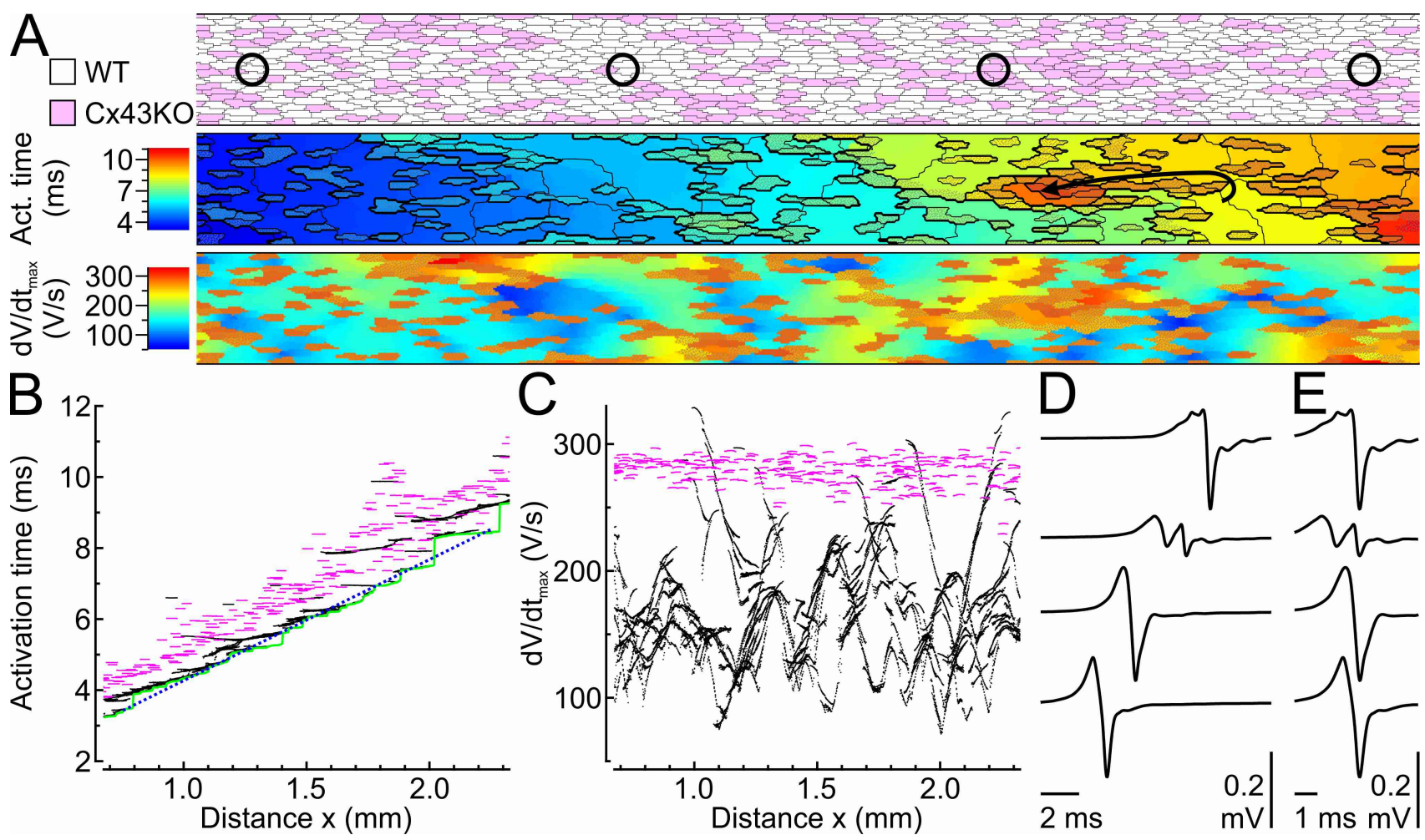

Figure 3. Propagation in one realization of the tissue model combining 30\% Cx43KO and 70\% WT cells (strand width: $150 \mu \mathrm{m}$ ). (A) Maps of cellular architecture, activation time (isochrone interval: $0.25 \mathrm{~ms}$ ) and $d V / d t_{\max }$. Cx43KO cells are shown in magenta or with a dotted texture. The arrow indicates retrograde conduction. (B) Activation time vs. distance. Data points in black and magenta correspond to nodes in WT and CX43KO cells, respectively. Green line: earliest activation time (EAT). Dotted blue line: linear fit of EAT $(C V=29.3 \mathrm{~cm} / \mathrm{s}) .(C) d V / d t_{\max } v$ s. distance. (D) Simulated electrograms that would be recorded by electrodes shown as circles in A. (E) Electrograms aligned on activation time.

The dispersion of activation times in the transverse direction and the occasional occurrence of retrograde propagation rendered impossible to use linear regression of all activation times to compute CV. Therefore, we considered only the furthermost position of the wavefront (earliest activation time, EAT) to represent its overall motion. The corresponding curve had a staircase-like aspect. Linear regression of EAT yielded a CV of $29.3 \mathrm{~cm} / \mathrm{s}$. 
Figure 4 and Video 2 illustrate conduction in a strand with 70\% of Cx43KO cells. Propagation occurred essentially in poorly coupled tissue because isolated WT cells were also poorly coupled to their Cx43KO neighbours. However, larger WT cell clusters randomly formed well-coupled regions. Transitions from a region with low coupling into a region with normal coupling are characterized by a prominent current-to-load mismatch which can lead to large conduction delays or even conduction block [1]. Thus, rather than accelerating conduction, WT cell clusters formed electrical loads that exhibited delayed activation with a low $\mathrm{dV} / \mathrm{dt}_{\mathrm{max}}$, which impaired conduction. Two such clusters are visible in Figure 4A (arrows). Consequently, CV was very slow $(2.95 \mathrm{~cm} / \mathrm{s})$. Electrograms were highly fractionated, combining the signal arising from propagation through poorly coupled tissue with contributions of WT cell clusters.

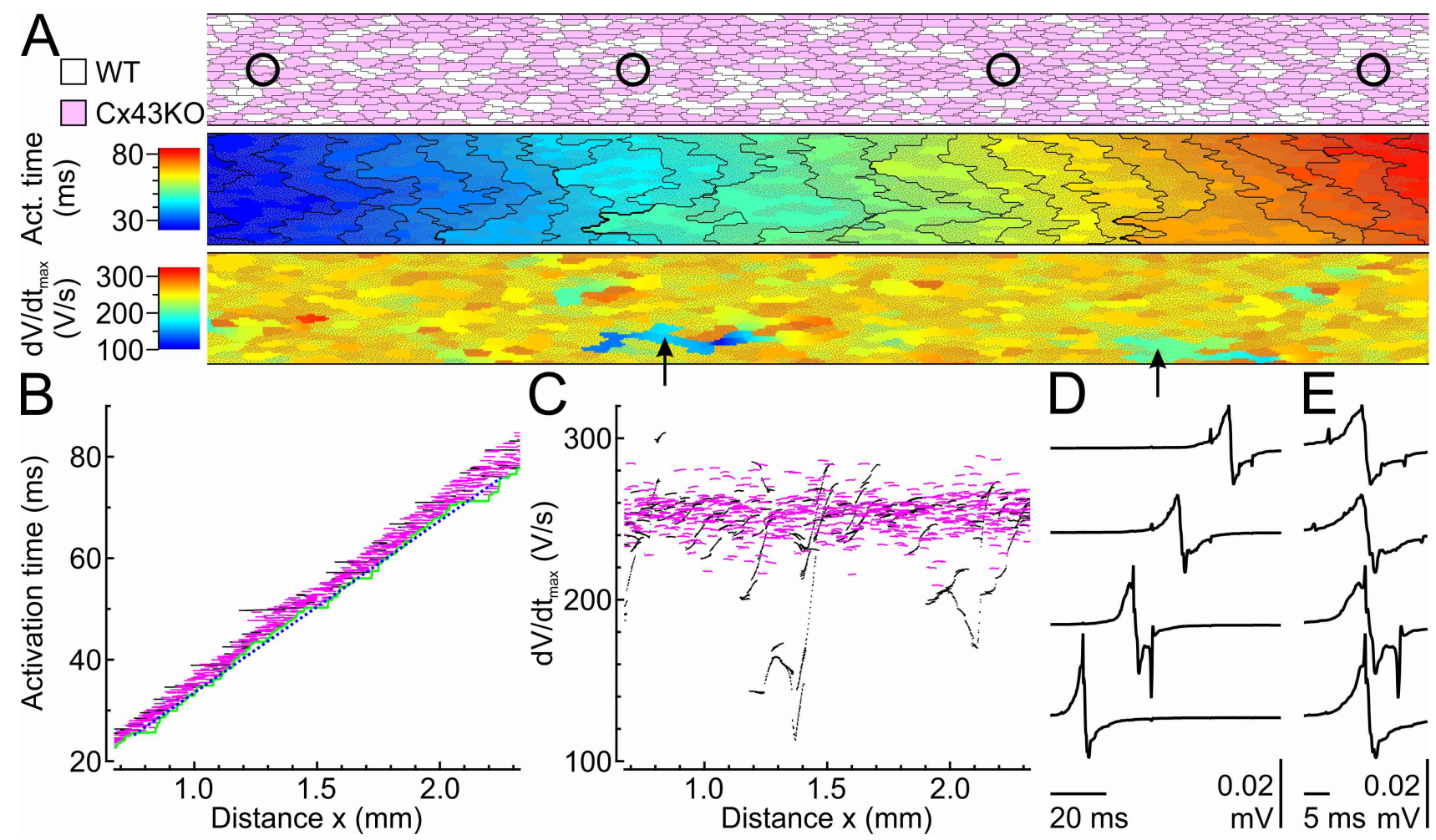

Figure 4. Propagation in one realization of the tissue model combining $70 \%$ Cx43KO and 30\% WT cells (strand width: $150 \mu \mathrm{m}$ ). Same layout as in Figure 3 (note the different ordinate scales). Isochrone interval: $2.5 \mathrm{~ms}$. CV=2.95 cm/s. The arrows in A denote two clusters of WT cells that formed electrical loads with delayed activation and low $d V / d t_{\text {max }}$.

Conduction block, including unidirectional block (UDB), was observed in some simulations combining WT and Cx43KO cells, as shown in Figure 5 and Videos 3 and 4 for one realization of a strand with a Cx43KO content of 50\%. During anterograde propagation (left to right), propagation was extremely tortuous, with a substantial delay along an oblique resistive barrier formed by Cx43KO cells that spanned the entire strand width (visible in the middle of Figure 5). During retrograde propagation (strand stimulated at the other end), this cell barrier caused conduction block. This block can be explained by a density of WT cells that was locally higher on the left side of the barrier than on the right side, which led to a more prominent current-to-load mismatch during retrograde propagation. Thus, conduction blocks resulted from the combination of the two deleterious mechanisms described in Figures 3 and 4: current-to-load mismatch consecutive to 
wavefront meandering and current-to-load mismatch at transitions from poorly coupled to wellcoupled regions.

Propagation in simulated control strands with Cx43KO cell contents of $0 \%$ and $100 \%$ is illustrated in the supplementary material (Figures S2 and S3, and Videos 5 and 6, respectively).

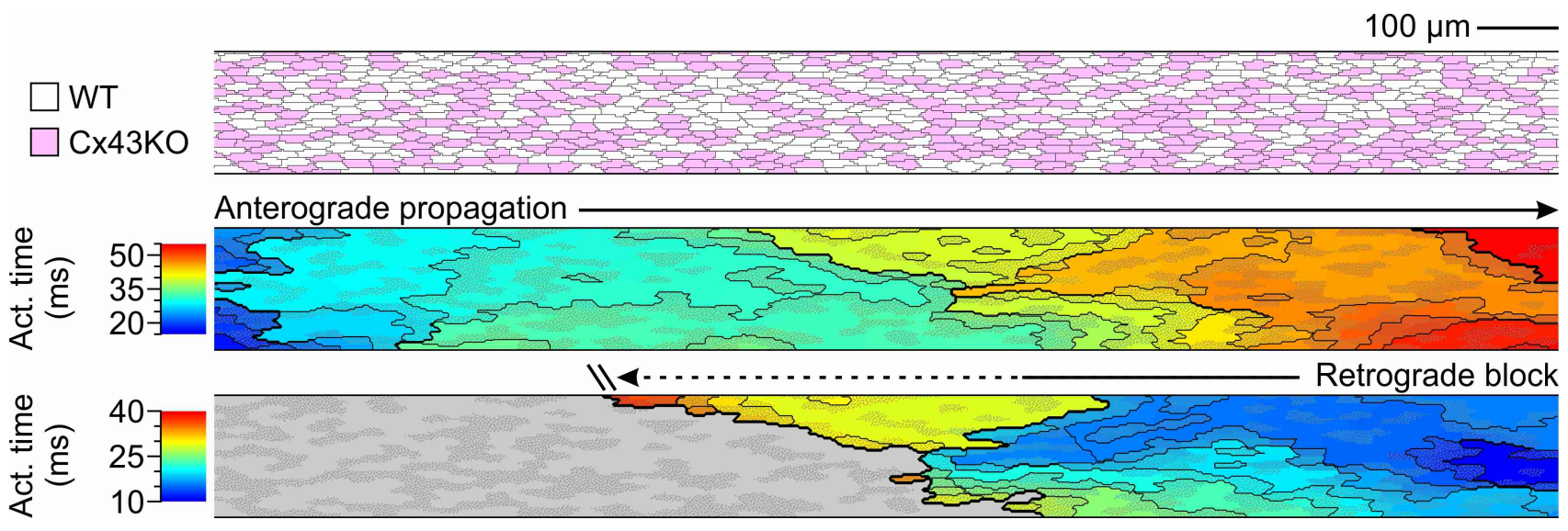

Figure 5. Unidirectional block in one realization of the tissue model combining $50 \%$ Cx43KO and 50\% WT cells (strand width: $150 \mu \mathrm{m}$ ). (Top) Map of cellular architecture. CX43KO cells are shown in magenta. (Middle and Bottom) Activation maps during anterograde propagation and retrograde block (isochrone interval: $0.25 \mathrm{~ms}$ ). Cx43KO cells are shown with a dotted texture. Unexcited cells are shown in grey.

\subsection{Systematic analysis of conduction in simulated tissues}

For every Cx43KO content and for strand widths of 150 and $60 \mu \mathrm{m}$, simulations were repeated 100 times with different realizations of cellular architecture. As shown in Figure 6A, the simulations using the LR1 model with enhanced $\mathrm{Ca}^{2+}$ current $\left(\mathrm{I}_{\mathrm{Ca}}\right)$ reproduced the nonlinear decrease of $\mathrm{CV}$ with increasing $\mathrm{Cx} 43 \mathrm{KO}$ content observed experimentally. The simulations also reproduced the increase of $\mathrm{CvarCT}_{0.5 \mathrm{~mm}}$ for $\mathrm{Cx} 43 \mathrm{KO}$ contents of $30-60 \%$. Globally, in $60 \mu \mathrm{m}$ wide strands, CV was slightly lower and $\mathrm{CvarCT}_{0.5 \mathrm{~mm}}$ was slightly larger than in $150 \mu \mathrm{m}$ wide strands (not statistically significant).

For the analysis of block, the latter was defined as failure of the wavefront to reach the distal end of an observation window spanning $25 \%$ to $75 \%$ of strand length. UDBs were counted as the number of cases with anterograde block within the observation window and successful retrograde propagation across this window. Figure 6A shows that the susceptibility to block was maximal for Cx43KO contents near $50 \%$. The probability of block was significantly lower in the $150 \mu \mathrm{m}$ wide strands than in the $60 \mu \mathrm{m}$ wide strands, which is explained by the presence of more alternative pathways permitting to bypass a local barrier to conduction. UDBs occurred in up to $9 \%$ of the 150 $\mu \mathrm{m}$ wide strands and in up to $11 \%$ of the $60 \mu \mathrm{m}$ wide strands.

In Figure 6B, the same analysis was conducted for simulations with the original LR1 formulation. The principal effect of reverting to this original formulation was to greatly increase the probability of block, which reached $100 \%$ at Cx43KO contents of $50-60 \%$. Thus the model with enhanced $\mathrm{I}_{\mathrm{Ca}}$ reproduced better the experimental observations. 

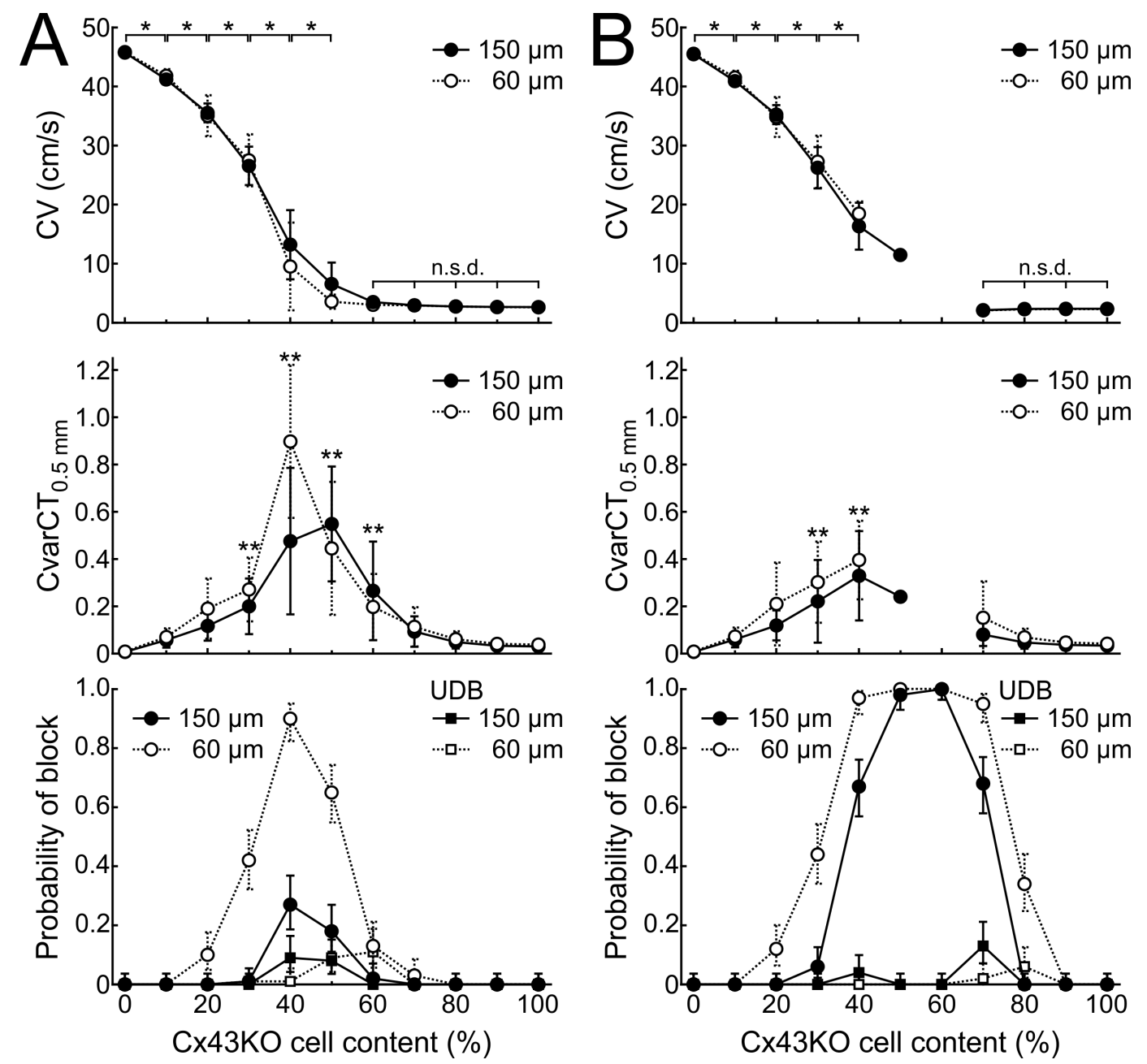

Figure 6. Conduction characteristics vs. Cx43KO cell content in simulated tissues. (A) CV, CvarCT $_{0.5 \mathrm{~mm}}$ and probability of block in simulations with the LR1 model with enhanced $I_{\text {Ca. }}$ Error bars for probability of block represent 95\% confidence intervals. Square symbols indicate the probability of UDB. (B) Same as A, for the original LR1 model. *: $\mathrm{p}<0.05$. n.s.d.: not significantly different. **: $\mathrm{p}<0.05$ vs. both $0 \%$ and $100 \%$ Cx43KO. Box plots of these data with numbers of simulations without block are presented in the supplementary material (Figure S4).

This sensitivity of conduction on $\mathrm{I}_{\mathrm{Ca}}$ and the fact that ion current densities differ between species and between healthy vs. diseased myocardium motivated us to analyse how conduction at various Cx43KO contents is affected by scaling individual ion currents. The set of simulations in $150 \mu \mathrm{m}$ wide strands (LR1 model with enhanced $\mathrm{I}_{\mathrm{Ca}}$ ) served as reference. Figure 7 shows relative $\mathrm{CV}$ changes and the proportion of blocks that were obtained upon increasing or decreasing the $\mathrm{Na}^{+}$ current $\left(\mathrm{I}_{\mathrm{Na}}\right)$, $\mathrm{I}_{\mathrm{Ca}}$, the time dependent $\mathrm{K}^{+}$current $\left(\mathrm{I}_{\mathrm{K}}\right)$, the plateau $\mathrm{K}^{+}$current $\left(\mathrm{I}_{\mathrm{Kp}}\right)$ or the inwardly rectifying $\mathrm{K}^{+}$current $\left(\mathrm{I}_{\mathrm{K} 1}\right)$. Increasing $\mathrm{I}_{\mathrm{Na}}$ or $\mathrm{I}_{\mathrm{Ca}}$ accelerated conduction and decreased the proportion of blocks. Decreasing these currents had opposite effects. Because recent work [23] shows that Cx43 is an important regulator of $\mathrm{I}_{\mathrm{Na}}$ and that $\mathrm{I}_{\mathrm{Na}}$ is altered in CX43KO cells, we also simulated $\mathrm{I}_{\mathrm{Na}}$ changes in Cx43KO cells only. In this situation, the effects became manifest only at Cx43KO cell contents $\geq 40 \%$. Increasing $\mathrm{I}_{\mathrm{K}}$ or $\mathrm{I}_{\mathrm{Kp}}$ depressed conduction by opposing inward currents at the beginning of the plateau. Conversely, decreasing these currents facilitated conduction. Doubling $\mathrm{I}_{\mathrm{K} 1}$ depressed conduction via resting membrane hyperpolarization (by $1.8 \mathrm{mV}$ ) and thus by increasing the electrical 
load. Halving $\mathrm{I}_{\mathrm{K} 1}$ facilitated conduction via resting membrane depolarization (by $3.9 \mathrm{mV}$ ) closer to threshold (supernormal conduction effect [3]). Halving $\mathrm{I}_{\mathrm{K} 1}$ also relieved all conduction blocks.

Interestingly, for all ion current modifications, the resulting effects were always more pronounced for $\mathrm{Cx} 43 \mathrm{KO}$ cell contents near $50 \%$ vs. $0 \%$ and $100 \%$. Furthermore, the variability of the effect was maximal for $\mathrm{Cx} 43 \mathrm{KO}$ cell contents near $50 \%$. Thus, conduction in heterogeneous tissue is generally more sensitive to changes in any ion current.

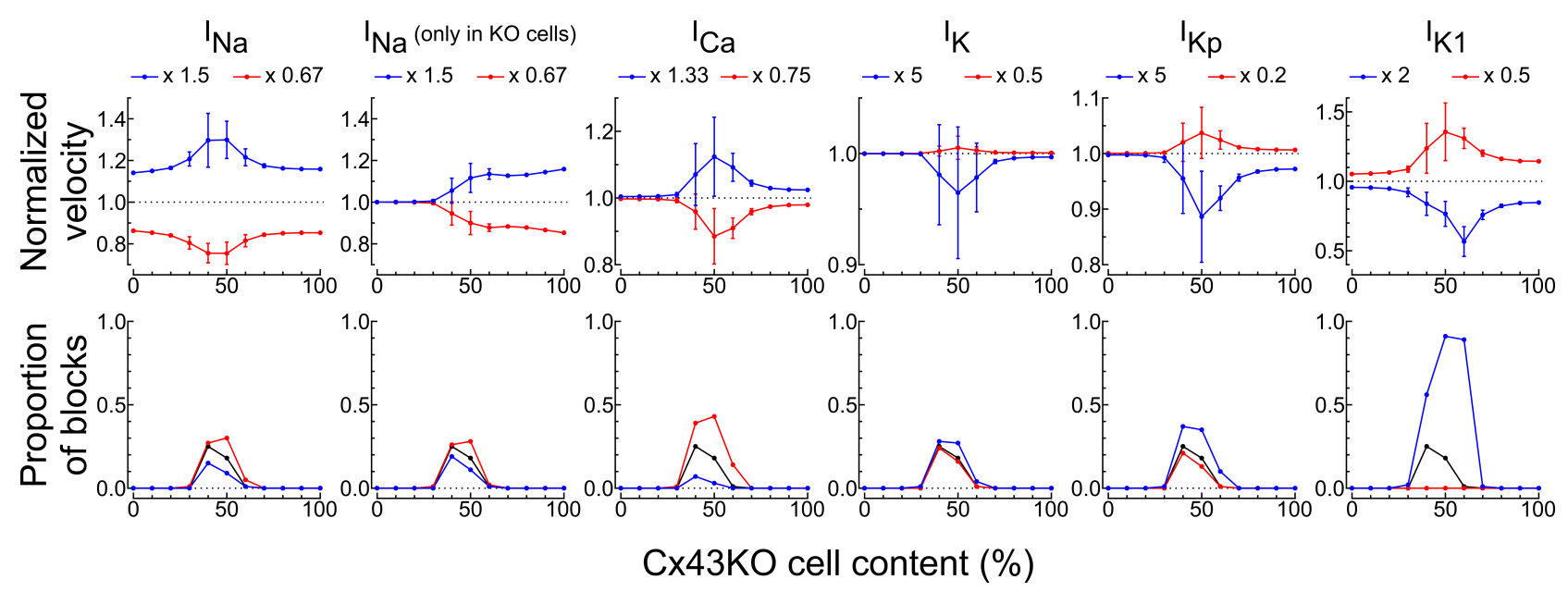

Figure 7. Effects of scaling individual ion currents on conduction as a function of Cx43KO cell content. $C V$ was normalized in respect to reference simulations (note the different ordinate scales). Scaling factors are shown above the plots. Data for the reference model are shown in black. $I_{N a}$ was scaled either in all cells (first column) or only in Cx43KO cells (second column). The other currents were scaled in all cells.

\subsection{Power-law behaviour of conduction heterogeneity}

The self-similar staircase-like activation patterns observed in simulations prompted us to investigate how CvarCT $_{\mathrm{d}}$ depends on the sampling distance $d$. While $d$ was fixed in the experiments $(0.5 \mathrm{~mm})$, it could be varied arbitrarily in the simulations. In double logarithmic plots, $\log \left(\mathrm{CvarCT}_{\mathrm{d}}\right)$ was linearly related to $\log (d)$ as shown in Figure $8 \mathrm{~A}$. Thus $\mathrm{CvarCT}_{\mathrm{d}}$ is a power function of $d$ with an exponent corresponding to the regression slope, S. Figure 8B shows that $\mathrm{S}$ was near -1 for $\mathrm{Cx} 43 \mathrm{KO}$ cell contents of $0 \%$ and $100 \%$ and it was significantly different for Cx43KO cell contents of $30-60 \%$.

Power-law behaviours are typical for fractal objects. One approach to quantify self-similarity is to determine the Hurst exponent [22]. The slopes (S) calculated in Figure 8 are mathematically related to the corresponding Hurst exponents $(\mathrm{H})$ as $\mathrm{S}=\mathrm{H}-1$ (see supplementary material). The Hurst exponent was near 0 for tissues composed of one cell type and it increased to 0.5 for $\mathrm{Cx} 43 \mathrm{KO}$ cell contents near $50 \%$. This confirms the fractal aspect of conduction in such tissue configurations.

In Figure 8B, we also determined the intercepts of the regression lines with the line defined by $\mathrm{CvarCT}_{\mathrm{d}}=1$. These intercept values can be regarded as a marker of the coarseness of the propagation pattern. The intercept was smaller than cell length for Cx43KO cell contents near 0 and $100 \%$. However, for $\mathrm{Cx} 43 \mathrm{KO}$ cell contents of $30-60 \%$, the intercept increased up to $150 \mu \mathrm{m}$, corresponding to multicellular scales. These large scales reflect the patchy aspect of propagation patterns in these tissue architectures, in which distinct patches were activated almost simultaneously, but with large delays in between. 

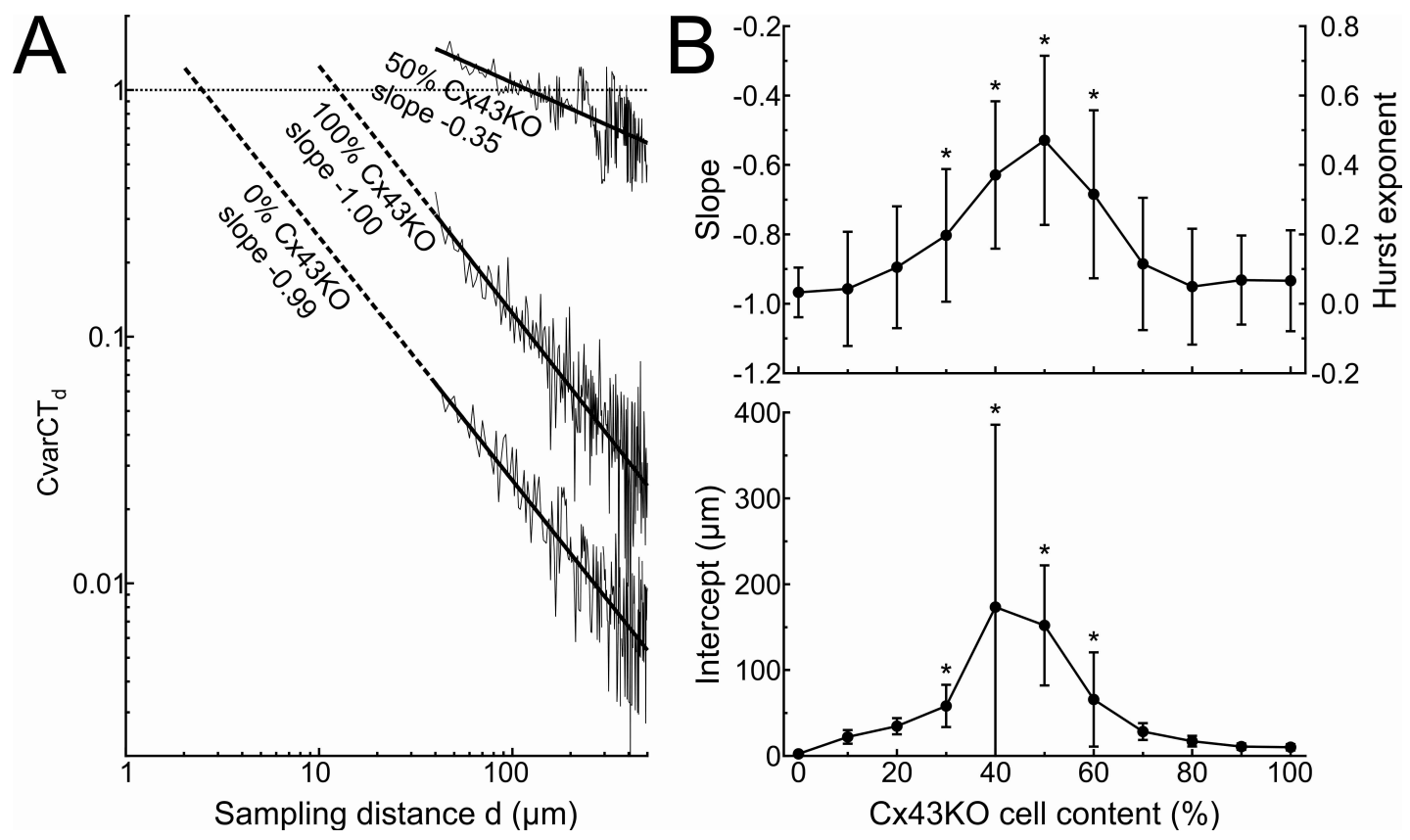

Figure 8. Power-law dependence of CvarCT $T_{d}$ vs. $d$. (A) Double logarithmic plots of CvarCT $T_{d}$ vs. $d$ for individual simulated strands (width: $150 \mu \mathrm{m}$ ) with $0 \%, 50 \%$ and 100\% Cx43KO cells. Labels indicate the slopes of the regression lines. (B) Slopes, Hurst exponents and intercepts of the regression lines at $\mathrm{CvarCT}_{d}=1 .{ }^{*}: \mathrm{p}<0.05 \mathrm{vs}$. both $0 \%$ and $100 \% \mathrm{CX} 43 \mathrm{KO}$. Box plots of the data in B are presented in the supplementary material (Figure S5).

\subsection{Conduction heterogeneity and block is due to the bimodal distribution of $\mathrm{Cx} 43$ expression}

We also investigated conduction in tissues with other paradigms of connexin expression: a uniform distribution of $\mathrm{Cx} 43$ expression between 0 and 100\%, an exponential distribution of a low level of Cx43 expression, and a complete uncoupling of either longitudinal or transverse intercellular junctions. Results are presented in the supplementary material (subsection 2.3). Interestingly, none of these paradigms resulted in conduction blocks or in manifestly heterogeneous conduction, indicating that in strands combining WT and Cx43KO genotypes, conduction heterogeneity and block are due to the bimodal distribution of the level of connexin expression.

\section{Discussion}

Our first principal finding is that in cardiac tissue combining cells expressing normal and low connexin levels, CV depends in a nonlinear manner on the relative proportion of the two cell types. Second, we observed that conduction in tissue composed of either WT or Cx43KO cells is homogeneous, but conduction becomes heterogeneous when these cells are combined. Third, we observed that conduction in such cellular combinations is highly prone to block, with $\mathrm{CV}$ and the susceptibility to block (including UDB) being particularly sensitive to changes in both inward and outward ion currents. Because slow conduction and UDB are key mechanisms of re-entry [1], cardiac tissues consisting of cellular mixtures with a bimodal distribution of connexin expression levels form highly arrhythmogenic substrates. Our simulations also reveal that the spatial distribution pattern of connexin expression in heterogeneous tissue can strongly affect propagation and cause block by building cellular arrangements potentiating current-to-load mismatch. 


\subsection{Comparison with previous experimental work}

Intriguingly, our results are different from those of Beauchamp and colleagues [6]. In their study, conduction decreased linearly with $\mathrm{Cx} 43 \mathrm{KO}$ cell content, such that for a Cx43KO cell content of $50 \%$, CV was about the average of that in $0 \%$ and $100 \%$ Cx43KO strands, and no conduction block was reported. In contrast, we observed a low CV at a Cx43KO cell content of $50 \%$ in both experiments and simulations ( $>5$ times slower than in WT strands), and the occurrence of block was manifest.

Several factors may explain this discrepancy. First, we consistently measured CV at the end of a 1-min pacing protocol. This approach was motivated by our previous finding in ventricular cell cultures that $\mathrm{CV}$ reaches steady state values only after 1 min of pacing [24]. In that work, we also observed that at sites of current-to-load mismatch, the degree of conduction block increases progressively during pacing at a moderate rate, a phenomenon probably mediated by intracellular $\mathrm{Na}^{+}$and $\mathrm{Ca}^{2+}$ accumulation. Beauchamp and colleagues [6] paced their preparations at a cycle length of 500 ms (André Kléber, personal communication), vs. 300 ms in our study. Thus, the different CV and block behaviours may be attributable to different pacing cycle lengths. Second, we note that our CV measurements in control WT strands are in close agreement with anterior studies of Kléber and colleagues [5,25], but not with those in their latest study [6], in which control CV was about 30\% lower. This suggests that the electrophysiological properties of the preparations were different in this latter study or that the basal level of Cx43 expression in WT myocytes was lower, which may explain a more linear relationship between CV and Cx43KO cell content. The use of neonatal GFPtagged myocytes instead of foetal WT myocytes might have represented another confounding factor. In addition, the age of the preparations was different (3-5 days in [6] vs. 3 days in our study), which may be associated with different ion channel expression levels. Different ion current densities (especially $\mathrm{I}_{\mathrm{K} 1}$ ) may have a large impact on the occurrence of block (Figure 7). Third, Beauchamp and colleagues [6] measured electrical activity over a distance of about $2 \mathrm{~mm}$, while we mapped propagation over a longer distance of $5.5 \mathrm{~mm}$. This difference in measurement scale explains why blocks were more likely to be detected using our approach.

\subsection{Homogeneous vs. heterogeneous uncoupling}

Shaw and Rudy [2] showed that homogenous intercellular uncoupling drastically slows conduction while paradoxically increasing its safety. They also demonstrated the importance of $\mathrm{I}_{\mathrm{Ca}}$ for this type of slow conduction. However, this study was based on one-dimensional fibres and assumed idealized uniform cell shapes and idealized patterns of intercellular coupling. Numerous other studies actually consider cardiac tissue as a continuum.

Such idealized situations do not pertain any longer when the fine detail of tissue structure starts to play a role. To investigate the consequences of naturally irregular cellular arrangements, Spach and Heidlage [26] as well as Henriquez and colleagues [27,28] developed models discretizing cardiac tissue at the subcellular level. They observed that stochastic microscopic irregularities cancel out through various mechanisms and conduction appears macroscopically continuous. However, it was shown that continuous models do not accurately predict the behaviour of conduction at abrupt transitions between tissue regions with different properties (e.g., different cell orientations) [28].

In our study, continuous models failed to replicate our experimental observations. In such models, the cellular structure is neglected and tissue conductivity is assumed to be spatially homogeneous. Therefore, propagation of planar wavefronts is characterized by parallel equidistant linear isochrones, a perfectly linear activation profile, an absence of $\mathrm{dV} / \mathrm{dt}_{\max }$ fluctuations and, most importantly, an absence of localized conduction blocks. Therefore, we had to recourse to a twodimensional detailed tissue model. Besides reproducing the irregular behaviour of conduction as well 
as the propensity to block observed experimentally, the model also reproduced the irregular shapes of extracellular electrograms. Thus, in tissue consisting of heterogeneously coupled cells, the detailed cellular configuration is an important determinant of conduction characteristics.

\subsection{Fractal characteristics of conduction}

In simulations with Cx43KO contents near 50\%, conduction exhibited self-similar discontinuous activation profiles. This fractal aspect was confirmed by finding Hurst exponents different from 0 . Fractal spatiotemporal patterns were previously reported for dynamical systems at critical phase transitions, including percolation phenomena [22]. Percolating systems and models are characterized by a critical connectivity threshold at which large clusters appear and allow for long-range connections. This suggests that the mixed WT/Cx43KO culture model may be assimilated to a percolating system with a phase transition near the 50\%/50\% Cx43KO/WT proportion.

It was previously proposed that the fractal aspect of the branching His-Purkinje system leads to a fractal activation pattern of the ventricles, reflected by a power spectrum of the QRS complex exhibiting a power-law behaviour [29]. Our study suggests that conduction may also exhibit fractal characteristics determined by the ultrastructure of cardiac tissue.

\subsection{Implications}

The most important implication of our work is that cardiac tissues composed of cells expressing different connexin levels form highly arrhythmogenic substrates with slow and unsafe conduction, contrasting with slow but safe conduction in homogeneously uncoupled tissue. Heterogeneous coupling occurs in diverse cardiac pathologies [13-17]. This gap junctional remodelling may be aggravated by fibrosis. Coupled fibroblasts or myofibroblasts reduce the resting potential of myocytes, as does a decrease of $\mathrm{I}_{\mathrm{K} 1}$; a large number of stromal cells ultimately lead to $\mathrm{I}_{\mathrm{Na}}$ inactivation $[9,10]$. Therefore, coupled stromal cells are likely to strongly influence conduction in heterogeneous tissues, as suggested by Figure 7. Heterogeneous coupling may possibly also occur during cellular therapies.

Our simulations support the notion that in heterogeneous substrates, the success of conduction is affected more strongly by changes in ion currents. This is relevant for pharmacotherapy because ion channels are frequent pharmacological targets. Our study also stresses the importance of modelling heterogeneous substrates at the cellular level because continuous homogenized models may be inappropriate.

\subsection{Limitations}

Because we were principally interested in conduction, we used the LR1 model rather than a more elaborate cellular electrophysiological model. Therefore, our study has the limitation that the modified LR1 model may not reproduce all electrophysiological aspects of foetal murine ventricular myocytes. However, our analysis of the sensitivity of conduction characteristics to ion current changes suggests that the results with the LR1 model remain qualitatively valid when ion currents are scaled. Nevertheless, the results can critically depend on the electrical phenotype of the investigated cells. Therefore, care must be taken when extrapolating the results to the adult mammalian heart and the human heart.

In the experiments, some uncertainty remains regarding the exact $\mathrm{Cx} 43 \mathrm{KO}$ cell content despite a careful cell counting. Mice expressing GFP can be used to identify the genotypes in the preparations [6], but this also has possible limitations as described above. Because of the close agreement between model and experiments, we nevertheless believe that the $\mathrm{Cx} 43 \mathrm{KO}$ cell contents were close to the desired proportions. Finally, we did not implement a bidomain formulation or incorporate the possibility of ephaptic conduction [30] in our model because of the large computational cost of such 
simulations. Because we simulated strands in a large bulk of extracellular space, and because the electrograms recorded in vitro have small amplitudes, we presume that specific effects induced by a bidomain formulation would be minor. Ephaptic conduction may modulate the results in a manner that is difficult to anticipate. This opens new prospects for further studies.

\section{Acknowledgments}

We are greatly indebted to Helene Hinnen for her assistance with genotyping and the preparation of the cultures, and to André Kléber for his invaluable comments.

This study was supported by the Swiss National Science Foundation (grant 31003A-135016/1 to J.P.K.).

\section{Disclosures}

None. 


\section{References}

[1] Kléber AG, Rudy Y. Basic mechanisms of cardiac impulse propagation and associated arrhythmias. Physiol Rev 2004;84:431-88.

[2] Shaw RM, Rudy Y. Ionic mechanisms of propagation in cardiac tissue. Roles of the sodium and L-type calcium currents during reduced excitability and decreased gap junction coupling. Circ Res 1997;81:727-41.

[3] Rohr S, Kucera JP, Kléber AG. Slow conduction in cardiac tissue, I: effects of a reduction of excitability versus a reduction of electrical coupling on microconduction. Circ Res 1998;83:781-94.

[4] Vaidya D, Tamaddon HS, Lo CW, Taffet SM, Delmar M, Morley GE, et al. Null mutation of connexin43 causes slow propagation of ventricular activation in the late stages of mouse embryonic development. Circ Res 2001;88:1196-202.

[5] Beauchamp P, Choby C, Desplantez T, de Peyer K, Green K, Yamada KA, et al. Electrical propagation in synthetic ventricular myocyte strands from germline connexin 43 knockout mice. Circ Res 2004;95:170-8.

[6] Beauchamp P, Desplantez T, McCain ML, Li W, Asimaki A, Rigoli G, et al. Electrical coupling and propagation in engineered ventricular myocardium with heterogeneous expression of connexin43. Circ Res 2012;110:1445-53.

[7] Ursell PC, Gardner PI, Albala A, Fenoglio JJ Jr, Wit AL. Structural and electrophysiological changes in the epicardial border zone of canine myocardial infarcts during infarct healing. Circ Res 1985;56:436-51.

[8] de Bakker JM, van Capelle FJ, Janse MJ, Tasseron S, Vermeulen JT, de Jonge N, et al. Slow conduction in the infarcted human heart: zigzag course of activation. Circulation 1993;88:91526.

[9] Miragoli M, Gaudesius G, Rohr S. Electrotonic modulation of cardiac impulse conduction by myofibroblasts. Circ Res 2006;98:801-10.

[10] Jacquemet V, Henriquez CS. Loading effect of fibroblast-myocyte coupling on resting potential, impulse propagation, and repolarization: insights from a microstructure model. Am J Physiol Heart Circ Physiol 2008;294:H2040-52.

[11] McLerie M, Lopatin AN. Dominant-negative suppression of I(K1) in the mouse heart leads to altered cardiac excitability. J Mol Cell Cardiol 2003;35:367-78.

[12] Davis LM, Rodefeld ME, Green K, Beyer EC, Saffitz JE. Gap junction protein phenotypes of the human heart and conduction system. J Cardiovasc Electrophysiol 1995;6:813-22.

[13] Kitamura H, Ohnishi Y, Yoshida A, Okajima K, Azumi H, Ishida A, et al. Heterogeneous loss of connexin43 protein in nonischemic dilated cardiomyopathy with ventricular tachycardia. J Cardiovasc Electrophysiol 2002;13:865-70.

[14] Boulaksil M, Winckels SK, Engelen MA, Stein M, van Veen TA, Jansen JA, et al. Heterogeneous Connexin43 distribution in heart failure is associated with dispersed conduction and enhanced susceptibility to ventricular arrhythmias. Eur J Heart Fail 2010;12:913-21.

[15] Huang XD, Sandusky GE, Zipes DP. Heterogeneous loss of connexin43 protein in ischemic dog hearts. J Cardiovasc Electrophysiol 1999;10:79-91. 
[16] Peters NS, Coromilas J, Severs NJ, Wit AL. Disturbed connexin43 gap junction distribution correlates with the location of reentrant circuits in the epicardial border zone of healing canine infarcts that cause ventricular tachycardia. Circulation 1997;95:988-96.

[17] Cabo C, Yao J, Boyden PA, Chen S, Hussain W, Duffy HS, et al. Heterogeneous gap junction remodeling in reentrant circuits in the epicardial border zone of the healing canine infarct. Cardiovasc Res 2006;72:241-9.

[18] Thibodeau IL, Xu J, Li Q, Liu G, Lam K, Veinot JP, et al. Paradigm of genetic mosaicism and lone atrial fibrillation: physiological characterization of a connexin 43-deletion mutant identified from atrial tissue. Circulation 2010;122:236-44.

[19] Gutstein DE, Morley GE, Vaidya D, Liu F, Chen FL, Stuhlmann H, et al. Heterogeneous expression of gap junction channels in the heart leads to conduction defects and ventricular dysfunction. Circulation 2001;104:1194-9.

[20] Jongsma HJ, Wilders R. Gap junctions in cardiovascular disease. Circ Res 2000;86:1193-7.

[21] Luo CH, Rudy Y. A model of the ventricular cardiac action potential. Depolarization, repolarization, and their interaction. Circ Res 1991;68:1501-26.

[22] Peitgen HO, Jürgens H, Saupe D. Chaos and Fractals: New Frontiers of Science. New York, NY: Springer-Verlag; 1992.

[23] Jansen JA, Noorman M, Musa H, Stein M, de Jong S, van der Nagel R, et al. Reduced heterogeneous expression of Cx43 results in decreased Nav1.5 expression and reduced sodium current that accounts for arrhythmia vulnerability in conditional Cx43 knockout mice. Heart Rhythm 2012;9:600-7.

[24] Kondratyev AA, Ponard JG, Munteanu A, Rohr S, Kucera JP. Dynamic changes of cardiac conduction during rapid pacing. Am J Physiol Heart Circ Physiol 2007;292:H1796-H811.

[25] Thomas SP, Kucera JP, Bircher-Lehmann L, Rudy Y, Saffitz JE, Kléber AG. Impulse propagation in synthetic strands of neonatal cardiac myocytes with genetically reduced levels of connexin43. Circ Res 2003;92:1209-16.

[26] Spach MS, Heidlage JF. The stochastic nature of cardiac propagation at a microscopic level. Electrical description of myocardial architecture and its application to conduction. Circ Res 1995;76:366-80.

[27] Kim JM, Bursac N, Henriquez CS. A computer model of engineered cardiac monolayers. Biophys J 2010;98:1762-71.

[28] Hubbard ML, Henriquez CS. Microscopic variations in interstitial and intracellular structure modulate the distribution of conduction delays and block in cardiac tissue with source-load mismatch. Europace 2012;14 Suppl 5:v3-v9.

[29] Goldberger AL, Bhargava V, West BJ, Mandell AJ. On a mechanism of cardiac electrical stability. The fractal hypothesis. Biophys J 1985;48:525-8.

[30] Mori Y, Fishman GI, Peskin CS. Ephaptic conduction in a cardiac strand model with 3D electrodiffusion. Proc Natl Acad Sci U S A 2008;105:6463-8. 


\section{Supplementary material}

\section{Nonlinear behaviour of conduction and block in cardiac tissue with heterogeneous expression of connexin 43}

Yann Prudat and Jan P. Kucera

Department of Physiology, University of Bern, Switzerland

\section{Detailed Materials and Methods}

\subsection{Electrophysiological experiments}

\subsubsection{Patterned murine ventricular cell cultures on microelectrode arrays}

Heterozygous germline connexin 43 knockout (Cx43KO) mice [1] (line kindly provided by André G. Kléber) were bred on a C57BL6/J background (Charles River Laboratories, Sulzfeld, Germany). As described previously [2,3], hearts were obtained from foetuses at postcoital day 19 (both parents heterozygous). Animals were handled in accordance with the ethical principles and guidelines of the Swiss Academy of Medical Sciences. The protocols were independently reviewed and approved by the Commission of Animal Experimentation of the Cantonal Veterinary Office of the Canton of Bern, Switzerland. The genotype of each foetus was determined by polymerase chain reaction. Ventricles were minced and digested enzymatically in separate Eppendorf tubes. The cell suspensions were preplated to minimize myofibroblast content. Subsequently, once the genotypes were determined, cells of the same genotype were pooled and the cells in each suspension were counted using a Neubauer chamber. Suspensions of Cx43KO and wild-type (WT) cells were then mixed to obtain predefined proportions of $\mathrm{Cx} 43 \mathrm{KO}$ cells $(\mathrm{Cx} 43 \mathrm{KO}$ content, from 0 to $100 \%$ in steps of $10 \%$ ) and seeded at a total density of $3.5 \cdot 10^{5} / \mathrm{cm}^{2}$ on microelectrode arrays (Centre Suisse d'Électronique et de Microtechnique, Neuchâtel, Switzerland) which were preconditioned for patterned growth with type I collagen (Sigma-Aldrich, Buchs, Switzerland) and mounted into custom culture chambers (diameter: $1.2 \mathrm{~cm}$ ) as previously described [4,5]. The patterns consisted of strands (width: 150-200 $\mu \mathrm{m}$; length: $0.7 \mathrm{~cm}$ ) passing over 12 extracellular electrodes (interelectrode distance: $0.5 \mathrm{~mm}$; diameter $40 \mu \mathrm{m}$ ) and 2 stimulation dipoles. The growth medium (M199 with Hanks' salts; Sigma-Aldrich, Buchs, Switzerland) was supplemented with streptomycin (20 mg/L, Oxoid, Pratteln, Switzerland) and penicillin (20000 U/L, Oxoid, Pratteln, Switzerland). Bromodeoxyuridine (100 $\mu \mathrm{mol} / \mathrm{L}$, Sigma-Aldrich, Buchs, Switzerland) was also added to inhibit myofibroblast proliferation. For each culture, strands with $100 \% \mathrm{WT}$ and/or $100 \%$ Cx43KO cells were also prepared as positive/negative controls. Heterozygous cells were not used in the co-cultures.

\subsubsection{Electrophysiological recordings}

Experiments were conducted with 3-day-old cultures. The preparations were inspected to verify their structural integrity and only intact strands were used. The growth medium was replaced with Hanks' balanced salt solution (Sigma-Aldrich, Buchs, Switzerland) and the chambers were mounted into a custom amplifier array [5] (gain: $1000 \times$ ) which was then placed into an incubator $\left(36^{\circ} \mathrm{C}, 0.9 \%\right.$ $\mathrm{CO}_{2}$ ). After an equilibration period $\geq 60 \mathrm{~min}$, extracellular unipolar electrograms were recorded (sampling rate: $10 \mathrm{kHz}$ ) during pacing at a cycle length of $300 \mathrm{~ms}$ with biphasic voltage pulses at 1.5-2 times threshold. This cycle length was optimal to overdrive the spontaneous activity of the preparations and to prevent that stimulation artefacts interfered with the electrograms recorded by the 
electrodes most distant from the pacing site during very slow conduction in strands with a high Cx43KO cell content.

\subsubsection{Determination of conduction velocity and heterogeneity}

At each electrode, activation times were defined as the times of occurrence of the minimum of the first derivative of the electrogram. CV was determined by linear regression of activation times vs. distance. As in a previous study [5], we observed that CV reaches steady state after approx. 1 min of pacing at a given cycle length. Therefore, the recordings were first inspected to verify that pacing stimuli were captured and that no spontaneous activity interfered with the recording. For each strand, $\mathrm{CV}$ was then determined as the mean $\mathrm{CV}$ during the last $10 \mathrm{~s}$ of a 1-min pacing protocol.

Conduction heterogeneity was quantified as the coefficient of variation (Cvar, ratio of standard deviation to mean) of conduction time (CT) between adjacent recording sites separated by a given distance $d$ (CvarCT $\mathrm{T}_{\mathrm{d}}$, with $d=0.5 \mathrm{~mm}$ in the experiments, corresponding to electrode spacing). CvarCT is 0 for perfectly homogeneous and uniform conduction and large CvarCT values indicate heterogeneous activation patterns.

\subsection{Computer simulations using a tissue model with cellular architecture}

\subsubsection{Cellular architecture}

Simulations of conduction were run in computer-generated two dimensional tissues mimicking cardiac cellular architecture. Based on the morphometric data of Thomas et al. in strands of murine ventricular cells [6], we assumed elongated cell shapes with an average length $L$ of $40 \mu \mathrm{m}$ and an average width $W$ of $10 \mu \mathrm{m}$, and thus a $L / W$ ratio $R$ of 4 and, for elliptical shapes, an area $A=$ $(\pi / 4) L W$. To generate the tissues, two dimensional domains (strands with a width of 60 or $150 \mu \mathrm{m}$ and a length of $3 \mathrm{~mm}$ ) were first populated with cell centroids seeded at random. The centroids were generated sequentially as illustrated in Figure S1A. First, a tentative centroid was selected as a random point in the domain. The centroid was then accepted when its distance to the closest of the already present centroids was larger than a predefined minimal value $M=0.8 \cdot A^{1 / 2}$ and rejected otherwise, and the operation was repeated until the number of centroids in the domain was $A_{\text {domain }} / A$, where $A_{\text {domain }}$ is the area of the domain. To account for elongated cell shapes with $R=4$, distance was measured here using a non-Euclidean metric defined by

$$
d s^{2}=\left(\begin{array}{ll}
d x & d y
\end{array}\right) g\left(\begin{array}{l}
d x \\
d y
\end{array}\right) \quad \text { with a metric tensor } \quad g=\left(\begin{array}{cc}
R^{-1} & 0 \\
0 & R
\end{array}\right) \text {, }
$$

where $d s$ is the length of a line element. From the centroids, the cell borders were then generated by Voronoi tessellation of the domain using the same metric, as shown in Figure S1B. The intercellular borders were subsequently classified as being longitudinal or transverse. For this classification, the angle $\alpha$ between a vector $v$ parallel to the cell border and a vector $n$ oriented along the strand direction was computed (using the metric tensor $g$ ) as

$$
\cos \alpha=\frac{v^{T} g n}{\sqrt{v^{T} g v} \sqrt{n^{T} g n}}
$$


and the cell border was classified as longitudinal if $|\alpha| \leq \pi / 4$ and transverse otherwise, as illustrated in Figure S1B. The genotypes of the cells were then allocated stochastically according to the binomial distribution defined by the proportion of WT and Cx43KO cells to simulate.

In the following, all lengths/distances refer to the ordinary Euclidean metric $d s^{2}=d x^{2}+d y^{2}$. On average, the tissue generation procedure yielded cells with $\mathrm{L}=41.9 \pm 5.2 \mu \mathrm{m}$ and $\mathrm{W}=11.5 \pm 1.5 \mu \mathrm{m}$. Each cell was connected longitudinally to $2.7 \pm 0.8$ cells and transversally to $3.1 \pm 0.8$ cells.
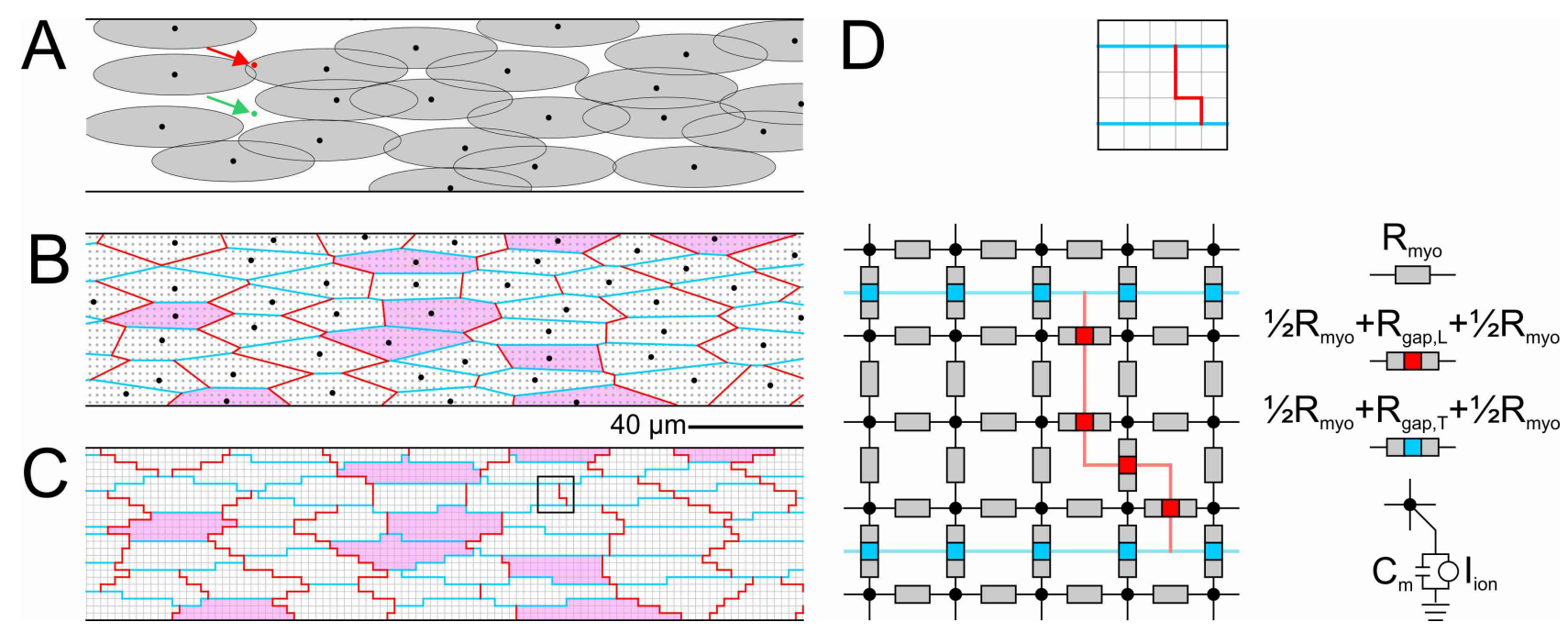

Figure S1. Computational tissue generation: example of a $60 \mu \mathrm{m}$ wide strand (a $250 \mu \mathrm{m}$ segment is shown). (A) Sequential seeding of cell centroids (dots). The ellipses denote regions that cannot be occupied by a new centroid. The centroid marked in red (arrow) is rejected; the one marked in green (arrow) is accepted. (B) Voronoi tessellation of the strand. Cells are coloured according to genotype (in this example: 20\% Cx43KO, magenta, and $80 \% \mathrm{WT}$, white). Red and blue lines denote longitudinal and transverse cell to cell contacts, respectively. The small grey dots denote the grid used for the subsequent discretization. (C) Network after discretization $(\Delta x=\Delta y=2.5 \mu \mathrm{m})$, with cells and cell-cell contacts coloured as in B. (D) Equivalent electric circuit for the small region marked in $C$. $R_{\text {myo }}$ : myoplasmic resistance; $R_{\text {gap }, L}$ and $R_{\text {gap }, T}$ : longitudinal and transverse gap junctional resistance, respectively. Individual nodes (black disks) are connected to membrane capacitance and model ionic currents $\left(I_{\text {ion }}\right)$.

\subsubsection{Capacitive and resistive properties}

We determined the capacitive and resistive properties of the tissue monolayer on the basis of our earlier investigation of conduction in heterozygous $\left(\mathrm{Cx}_{4} 3^{+/}\right)$neonatal murine ventricular cell strands [7]. In that study, propagation was simulated along a one-dimensional fibre of abutting idealized cylindrical cells having a diameter of $10 \mu \mathrm{m}$ (radius: $r=5 \mu \mathrm{m}$ ), a length $(I)$ of $40 \mu \mathrm{m}$ and a myoplasmic resistivity of $124 \Omega \mathrm{cm}$ (comparable to the resistivity of $150 \Omega \mathrm{cm}$ used by other authors $[8,9]$ and to experimentally determined values [10]). The geometrical area of the idealized cylindrical cell is $A_{\text {geo }}=2 \pi r^{2}+2 \pi r l\left(1417.72 \mu \mathrm{m}^{2}\right)$, its volume is $V=\pi r^{2} l\left(3141.59 \mu \mathrm{m}^{2}\right)$ and its geometrical surface to volume ratio is $A_{\mathrm{gee}} / \mathrm{V}\left(0.45 \mu \mathrm{m}^{-1}=4500 \mathrm{~cm}^{-1}\right)$. We assumed a ratio of capacitive to geometric area $R_{\mathrm{CG}}$ (reflecting membrane folding) of 2, as done by Luo and Rudy [11], which leads to a 
capacitive area $A_{\text {cap }}=\mathrm{R}_{\mathrm{CG}} \cdot A_{\text {geo }}$ of $2827.43 \mu \mathrm{m}^{2}$, a capacitive surface to volume ratio of $9000 \mathrm{~cm}^{-1}$ and, assuming a specific membrane capacitance $\left(\mathrm{C}_{\mathrm{m}}\right)$ of $1 \mu \mathrm{F} / \mathrm{cm}^{2}$, to a cell capacitance of $28.2743 \mathrm{pF}$. To derive parameters for the cellular monolayer, the ideal cylindrical cell was reshaped into a parallelepiped of the same length $(l=40 \mu \mathrm{m})$, width $(d=10 \mu \mathrm{m})$ and volume, and thus of a thickness $h=\mathrm{V} / \mathrm{ld}$ of $7.854 \mu \mathrm{m}$ and a myoplasmic resistance that remained unchanged (the cross section $\pi r^{2}=$ $d h$ remained the same). The thickness $h$ is comparable to previously reported values [6]. Membrane capacitance was projected on the same area (without affecting surface to volume ratios), yielding a monolayer capacitance per unit area $\mathrm{C}_{\text {monolayer }}=\mathrm{A}_{\text {cap }} /$ ld $\left(7.069 \mu \mathrm{F} / \mathrm{cm}^{2}\right)$. This capacitance accounts globally for the membranes situated on both sides of the cells forming the monolayer, for the lateral membranes between the cells, and for microscopic membrane folding. The electrical parameters of the monolayer tissue model are listed in Table S1.

Table S1. Constants of the tissue model.

\begin{tabular}{|c|c|}
\hline Cell thickness & $7.854 \mu \mathrm{m}$ \\
\hline Myoplasmic resistivity & $124 \Omega \mathrm{cm}$ \\
\hline Ratio of capacitive to geometric cell area $\left(\mathrm{R}_{\mathrm{CG}}\right)$ & 2 \\
\hline Geometrical surface to volume ratio & $4500 \mathrm{~cm}^{-1}$ \\
\hline Capacitive surface to volume ratio & $9000 \mathrm{~cm}^{-1}$ \\
\hline Specific membrane capacitance $\left(\mathrm{C}_{\mathrm{m}}\right)$ & $1 \mu \mathrm{F} / \mathrm{cm}^{2}$ \\
\hline Monolayer capacitance per unit area $\left(\mathrm{C}_{\text {monolayer }}\right)$ & $7.069 \mu \mathrm{F} / \mathrm{cm}^{2}$ \\
\hline $\begin{array}{l}\text { Conductivity of longitudinal (end-to-end) } \\
\text { intercellular junctions }\left(\gamma_{\mathrm{L}}\right)\end{array}$ & $0.5541 \mu \mathrm{S} / \mu \mathrm{m}$ \\
\hline $\begin{array}{l}\text { Conductivity of transverse } \\
\text { intercellular junctions }\left(\gamma_{\mathrm{T}}\right)\end{array}$ & $0.1529 \mu \mathrm{S} / \mu \mathrm{m}$ \\
\hline $\begin{array}{l}\text { Junctional scaling factor }(k) \text { for simulations } \\
\text { with predefined cellular genotypes: } \\
\text { between two WT cells: } \\
\text { between two Cx43KO cells: } \\
\text { between a WT cell and a Cx43KO cell: }\end{array}$ & $\begin{array}{l}1 \\
0.0012 \\
0.0012\end{array}$ \\
\hline $\begin{array}{l}\text { Junctional scaling factor }(k) \text { for simulations } \\
\text { with predefined distributions of cellular levels } \\
\text { of connexin expression: } \\
\text { between cell A and cell B: }\end{array}$ & $\begin{array}{l}\min \left(p_{\mathrm{A}}, p_{\mathrm{B}}\right) \\
\text { with } p \text { drawn randomly from a predefined } \\
\text { distribution }\end{array}$ \\
\hline
\end{tabular}

\subsubsection{Intercellular coupling}

Intercellular coupling conductance was set proportionally to the length of contact between adjacent cells using proportionality constants $\gamma_{\mathrm{L}}$ and $\gamma_{\mathrm{T}}$ for longitudinal and transverse contacts, respectively (Table S1). For contacts involving $\mathrm{Cx} 43 \mathrm{KO}$ cells, $\gamma_{\mathrm{L}}$ and $\gamma_{\mathrm{T}}$ were scaled by a specific factor $k$ (Table S1). The constants $\gamma_{\mathrm{L}}, \gamma_{\mathrm{T}}$ and $k$ were adjusted to reproduce the same longitudinal conduction velocity (CV) and the same maximal upstroke velocity ( $\left.\mathrm{dV}^{\mathrm{d}} \mathrm{dt}_{\mathrm{max}}\right)$ as reported previously in WT strands [2,6,7], an anisotropic CV ratio of 2 in WT tissue as reported for continuous monolayers [12], and the same CV observed previously in Cx43KO strands [2]. This adjustment was 
achieved by using $k=1$ for connections between WT cells and $k=0.0012$ between Cx43KO cells. Previous studies indicate that the residual gap junctional coupling between $\mathrm{Cx} 43 \mathrm{KO}$ cells is mediated by a low level of connexin 45 [2,13,14], and that heterotypic Cx43/Cx45 channels can form between WT and Cx43KO cells [3,15]. For connections between WT and Cx43KO cells, we therefore used $k=0.0012$ as well, assuming that electrical coupling is essentially determined by the cell expressing the least amount of connexins [3]. The constants pertaining to intercellular coupling are presented in Table S1. The model also reproduced the modest decrease of CV by only $\sim 10 \%$ observed previously in heterozygous strands [2,7] (in which Cx43 expression was found to be decreased by $43 \%$ ) when $k$ was set to 0.57 .

In additional simulations, other paradigms of heterogeneous gap junctional expression were tested. In these simulations, no particular genotype was attributed to the cells, but gap junctional expression (i.e., phenotype) was controlled by a parameter $p$ drawn randomly from a predefined distribution ( $p=0$ : no connexin expressed; $p=1$ : normal WT level of connexin expression). To determine gap junctional coupling between two neighbour cells, the junctional scaling factor $k$ was then set as the minimum value of $p$ of these two cells (see Table S1).

\subsubsection{Membrane currents}

Membrane currents were simulated with the Luo-Rudy phase 1 (LR1) model [16]. The $\mathrm{Na}^{+}$ current conductance was decreased from 23 to $13.5 \mu \mathrm{S} / \mathrm{cm}^{2}$ to replicate the rate of depolarization $\left(\mathrm{dV} / \mathrm{dt}_{\max }\right)$ reported previously [7]. In the original LR1 model, the L-type $\mathrm{Ca}^{2+}$ current (slow inward current) is small and activates very slowly. Therefore, its conductance was doubled and the kinetics of its activation and inactivation gates were accelerated 30 and 2 times, respectively, to yield a timeto-peak of $\sim 1 \mathrm{~ms}$ and a peak of $\sim 12 \mu \mathrm{A} / \mu \mathrm{F}$, comparable to previous observations and models $[11,17]$. The conductance of the time dependent $\mathrm{K}^{+}$current was increased from 0.282 to $0.5 \mu \mathrm{S} / \mathrm{cm}^{2}$ to produce a similar action potential duration as in the original model. The effect of reverting to the original LR1 formulation was evaluated in specific simulations.

\subsubsection{Tissue discretization}

The cellular network was then discretized using a Cartesian lattice with $\Delta x=\Delta y=2.5 \mu \mathrm{m}$ as illustrated in Figure S1C, resulting in an electric circuit equivalent as shown in Figure S1D. This discretization produced jagged intercellular connections (in particular at end-to-end junctions), similar to intercalated discs in vivo. Along each intercellular border, the coupling conductance calculated as described above was distributed evenly. At the border of the domain, Neumann boundary conditions were used.

\subsubsection{Numerical implementation, data analysis and reconstruction of extracellular electrograms}

Gating variables were integrated using the method of Rush and Larsen and membrane potential was computed at fixed time steps of $0.005 \mathrm{~ms}$. The diffusive part was solved using the alternating direction implicit method. Conduction was initiated by injecting a depolarizing current $\left(300 \mu \mathrm{A} / \mathrm{cm}^{2}\right)$ into the cells at the extremity of the strand. Activation time was defined at the occurrence of $\mathrm{dV} / \mathrm{dt}_{\max }$. Because the wavefront can assume an irregular shape, the progression of activation along the strand (as a function of distance $x$ ) was monitored by identifying the earliest activation time (EAT) at every coordinate $x$. CV was computed by linear regression of EAT vs. $x$ over an observation window spanning $25-75 \%$ of strand length to exclude boundary effects. 
To obtain a measure of conduction heterogeneity comparable to that in experiments, conduction heterogeneity was evaluated by sampling EAT at points separated by a distance $d=0.5 \mathrm{~mm}$ and by computing CvarCT . $_{\text {. }}$.

Extracellular potentials were computed as described previously [18]. Because the microelectrodes had a diameter of $40 \mu \mathrm{m}$, extracellular electrograms were reconstructed as the average extracellular potential on a disc with a diameter of $40 \mu \mathrm{m}$ situated $1 \mu \mathrm{m}$ off the plane of the tissue.

\subsubsection{Analysis of self-similarity and power-law behaviour of activation patterns}

To ascertain the presence of fractal activation patterns, the power-law dependence of CvarCT $_{d}$ on $d$ was then identified by examining CvarCT $_{\mathrm{d}}$ vs. $d$ in double logarithmic plots and by estimating the Hurst exponent (a measure of self-similarity [19]) of EAT( $x$ ).

CvarCT $_{d}$ was computed by sampling EAT( $x$ ) at regular intervals $d$ (from 40 to $250 \mu \mathrm{m}$ in steps of $2.5 \mu \mathrm{m}$ ) and by calculating, for each $d$, the ratio of the standard deviation to the mean of the conduction times over successive segments of length $d$ :

$C \operatorname{var} C T_{d}=\frac{\sigma(E A T(x+d)-E A T(x))}{\overline{C T}}$,

where $\sigma$ denotes the standard deviation and $\overline{C T}$ is the mean conduction time over a distance $d$. A linear relationship between $\log \left(\mathrm{CvarCT}_{\mathrm{d}}\right)$ and $\log (d)$ (in a double logarithmic plot) implies a powerlaw dependence of $\mathrm{CvarCT}_{\mathrm{d}}$ on $d$ :

$C \operatorname{var} C T_{d} \sim d^{S}$,

where the tilde sign denotes proportionality and the exponent $S$ corresponds to the regression slope in the double logarithmic plot. Because $\overline{C T}$ is related to overall conduction velocity $(C V)$ by $\overline{C T}=d / C V$, this proportionality can therefore also be expressed as

$\frac{d}{C V} C \operatorname{var} C T_{d}=\sigma(E A T(x+d)-E A T(x)) \sim d \cdot d^{S}=d^{S+1}$.

\subsubsection{Relationship between $S$ and the Hurst exponent of EAT(x)}

The Hurst exponent $H$ of a series $a(x)$ is a measure of self-similarity. It represents the power-law exponent describing the magnitude of fluctuations of $a$ observed at a given observation scale $\Delta x$ (i.e., a given level of detail) as a function of the observation scale itself $[19,20]$. It can be estimated on the basis of the following power-law [19,20]:

$\sigma(a(x+\Delta x)-a(x)) \sim \Delta x^{H}$.

$H$ can take values between 0 and 1 . Values of $H$ greater than 0 reflect the presence of a power-law behaviour and thus of statistical self-similarity.

We note that this power-law is very similar to the one we used to describe the dependence of $\operatorname{CvarCT}_{\mathrm{d}}$ on $d$. If we use $\operatorname{EAT}(x)$ and $d$ in place of $a(x)$ and $\Delta x$ and combine the last two equations, we obtain

$\sigma(\operatorname{EAT}(x+d)-\operatorname{EAT}(x)) \sim d^{S+1} \sim d^{H}$.

Thus, the estimation of the slope $S$ is related to the estimation of the Hurst exponent $H$, with $H=S+1$, i.e., $S=H-1$. 


\subsubsection{Effects of redistributing the $\mathrm{Na}^{+}$current conductance}

In specific control simulations, we examined the effect of redistributing the conductance of the voltage gated $\mathrm{Na}^{+}$current $\left(\mathrm{I}_{\mathrm{Na}}\right)$ to the nodes adjacent to either longitudinal or lateral junctions, without changing the total $\mathrm{I}_{\mathrm{Na}}$ conductance of the cells (the time step was reduced 10 times in these simulations). Conduction velocity differed by less than $1 \%$ in comparison to a uniform distribution of $\mathrm{I}_{\mathrm{Na}}$ conductance ( $\mathrm{n}=10$ randomly generated networks for every $\mathrm{Cx} 43 \mathrm{KO}$ cell content investigated) and activation sequences were identical. This result is in agreement with previous computational studies [21,22] in which $\mathrm{I}_{\mathrm{Na}}$ conductance was redistributed to intercellular junctions without taking hypothetical ephaptic interactions into account (i.e., negative extracellular potentials in intercellular clefts). This similar behaviour of conduction can be explained by the fact that within a given cell, the time scale of charge redistribution over the entire cell membrane (a few $\mu$ s) is considerably shorter than the time scale of the fastest electrophysiologically relevant phenomenon (i.e., $\sim 0.33 \mathrm{~ms}$ for depolarization by $100 \mathrm{mV}$ at a rate of $300 \mathrm{~V} / \mathrm{s}$ ) [23]. 


\section{Supplementary results}

\subsection{Simulations of conduction in the detailed model of cellular structure}

\subsection{1. $100 \%$ WT strand (0\% Cx43KO)}

Conduction in a computer-generated 100\% WT strand is shown in Figure S2 and Video 5. Despite the random distribution of cells and the presence of intercellular borders, the activation profile was smooth with a CV of $45.9 \mathrm{~cm} / \mathrm{s}$. No dispersion of activation times was manifest in the direction transverse to the strand axis. The cellular architecture introduced only minor fluctuations of $\mathrm{dV} / \mathrm{dt}_{\max }$ $(162.4 \pm 1.4 \mathrm{~V} / \mathrm{s})$. The extracellular electrograms exhibited a smooth biphasic shape with a uniform morphology. Conduction was therefore homogeneous.

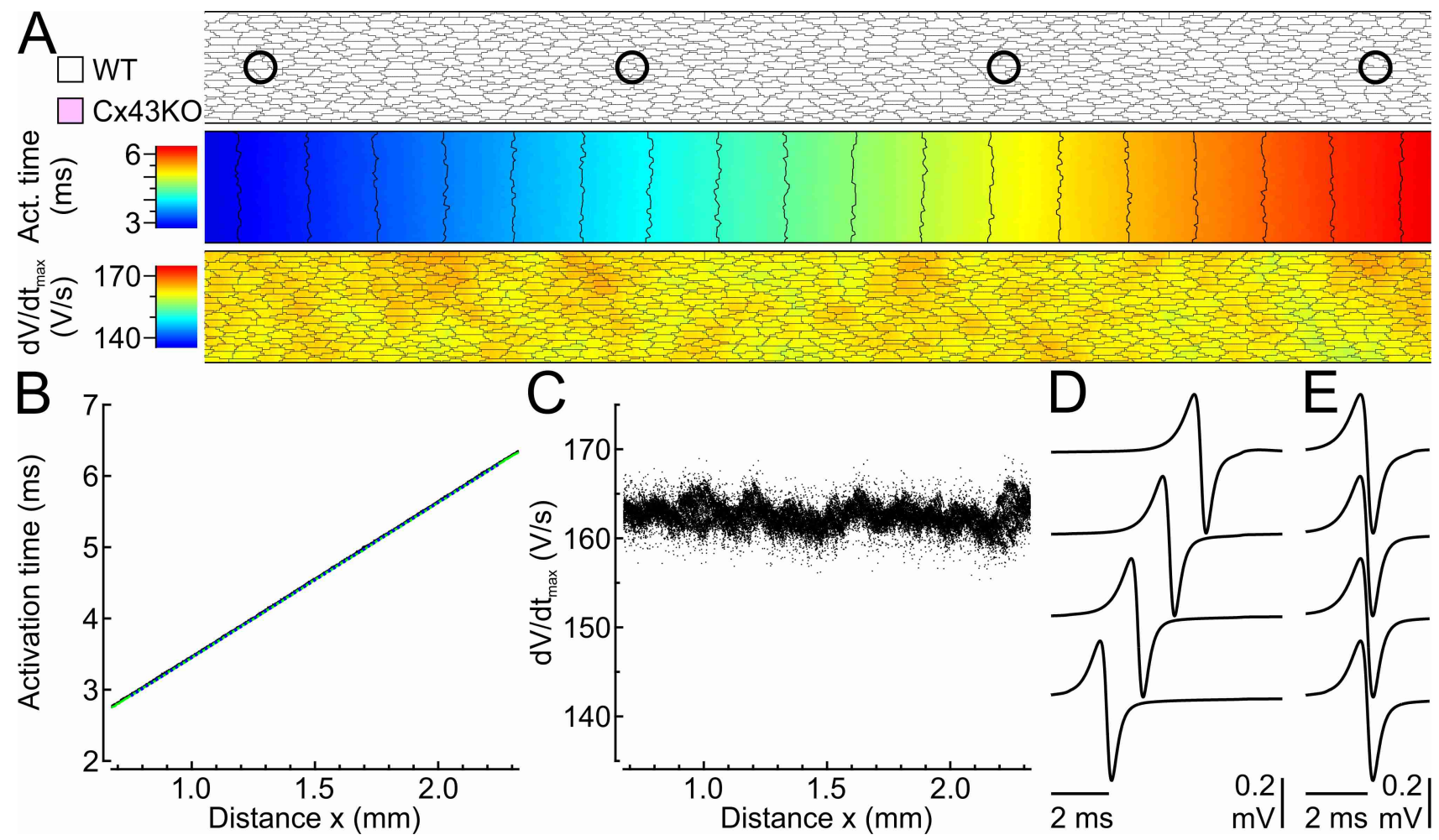

Figure S2. Control simulation of action potential propagation in one individual realization of the detailed tissue structure model with 100\% WT cells (strand width: $150 \mu \mathrm{m}$ ). Same layout as in Figures 3 and 4 of the main article. (A) Maps of cellular architecture, activation time (isochrone interval: $0.2 \mathrm{~ms}$ ) and $d V / d t_{\text {max }}$ (B) Activation time vs. distance $(C V=45.9 \mathrm{~cm} / \mathrm{s})$. (C) $d V / d t_{\max } v s$. distance. (D) Simulated electrograms that would be recorded by electrodes shown as circles in $A$. (E) Electrograms aligned on activation time. 


\subsection{2. $100 \%$ CX43KO strand}

Conduction in a computer-generated 100\% Cx43KO strand is presented in Figure S3 and Video 6. Conduction was slow $(2.64 \mathrm{~cm} / \mathrm{s})$, but no major propagation heterogeneity was apparent. Because of the low level of coupling, all the nodes within a given cell activated almost simultaneously. However, lateral neighbour cells were slightly desynchronized. In the direction transverse to the strand axis, this resulted in a slight dispersion of activation time, which is visible in the plot of activation time vs. distance (Figure S3B). In the longitudinal direction, activation proceeded with activation delays across intercellular borders. While the nodes within individual cells exhibited virtually the same $\mathrm{dV} / \mathrm{dt}_{\max }$, the low level of coupling and the cellular architecture led to an intercellular dispersion of $\mathrm{dV} / \mathrm{dt}_{\max }(253.3 \pm 8.0 \mathrm{~V} / \mathrm{s})$. This resulted in a typical aspect of the $\mathrm{dV} / \mathrm{dt}_{\max }$ map, with individual cells having distinct colours. Thus, the low level of gap junctional coupling introduced discontinuities at the cellular level, but conduction remained macroscopically homogeneous. Accordingly, the extracellular electrograms exhibited a jagged aspect (due to the individual activation of individual cells) but were separated by regular time intervals.

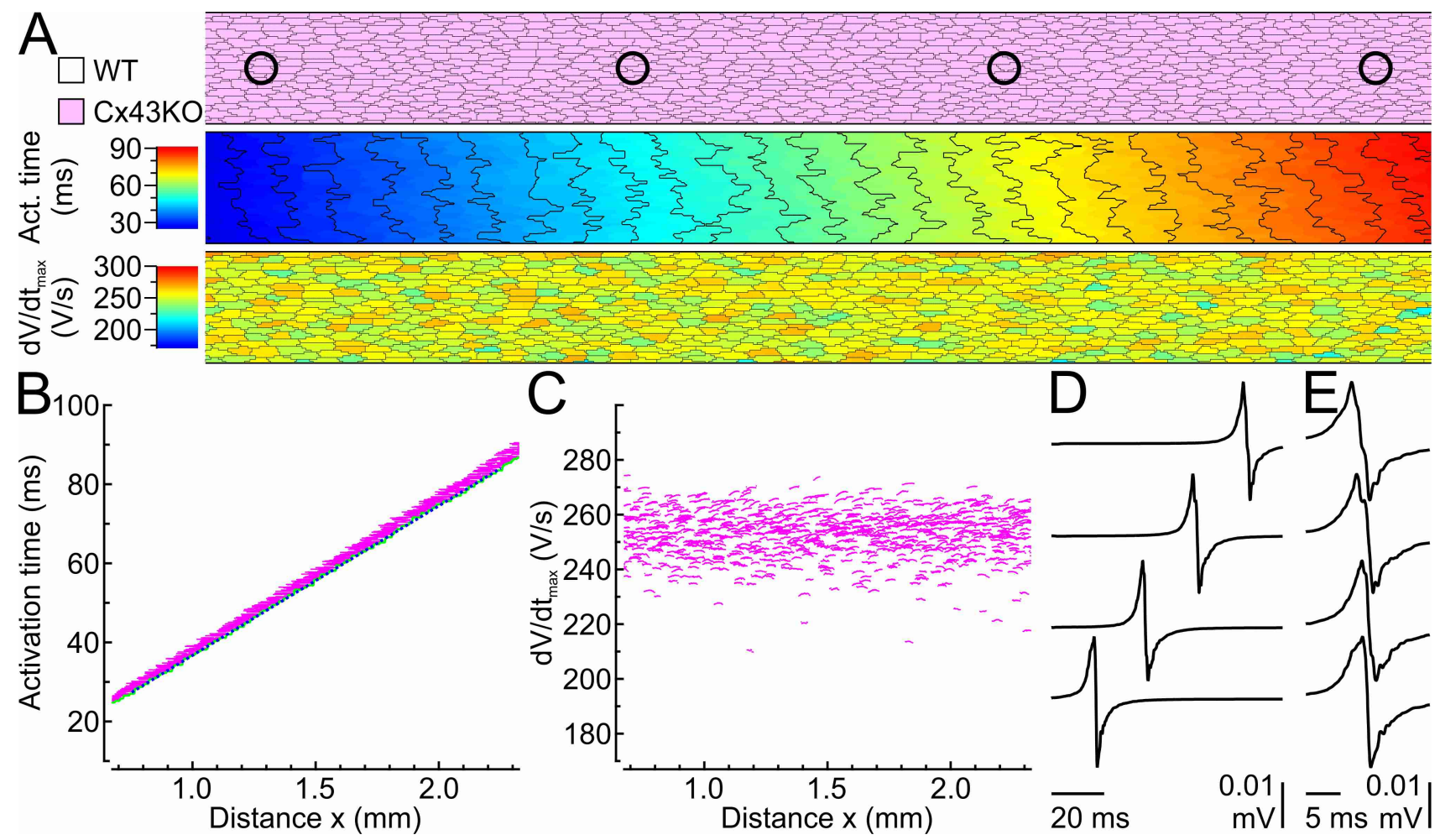

Figure S3. Control simulation of action potential propagation in one individual realization of the detailed tissue structure model with 100\% Cx43KO cells (strand width: $150 \mu \mathrm{m}$ ). Same layout as in Figures 3 and 4 of the main article. (A) Maps of cellular architecture, activation time (isochrone interval: $2.5 \mathrm{~ms}$ ) and $d V / d t_{\max }$ (B) Activation time vs. distance. Green line: earliest activation time (EAT). Dotted blue line: linear fit of EAT $(C V=2.64 \mathrm{~cm} / \mathrm{s}) .(C) d V / d t_{\max } v s$. distance. (D) Simulated electrograms that would be recorded by electrodes shown as circles in A. (E) Electrograms aligned on activation time. 


\subsection{Box plots of $C V, C v a r C T_{0.5}$ mm, regression slopes of $\log \left(C \operatorname{Cvar} C T_{d}\right)$ vs. $\log (d)$ and intercepts with $\mathrm{CVarCT}_{\mathrm{d}}=\mathbf{0}$ in simulations of conduction in the detailed model of cellular structure}

Tukey box plots of the data ( $\mathrm{CV}$ and $\left.\mathrm{CvarCT}_{0.5 \mathrm{~mm}}\right)$ presented in Figure 6 of the main article are shown in Figure S4.
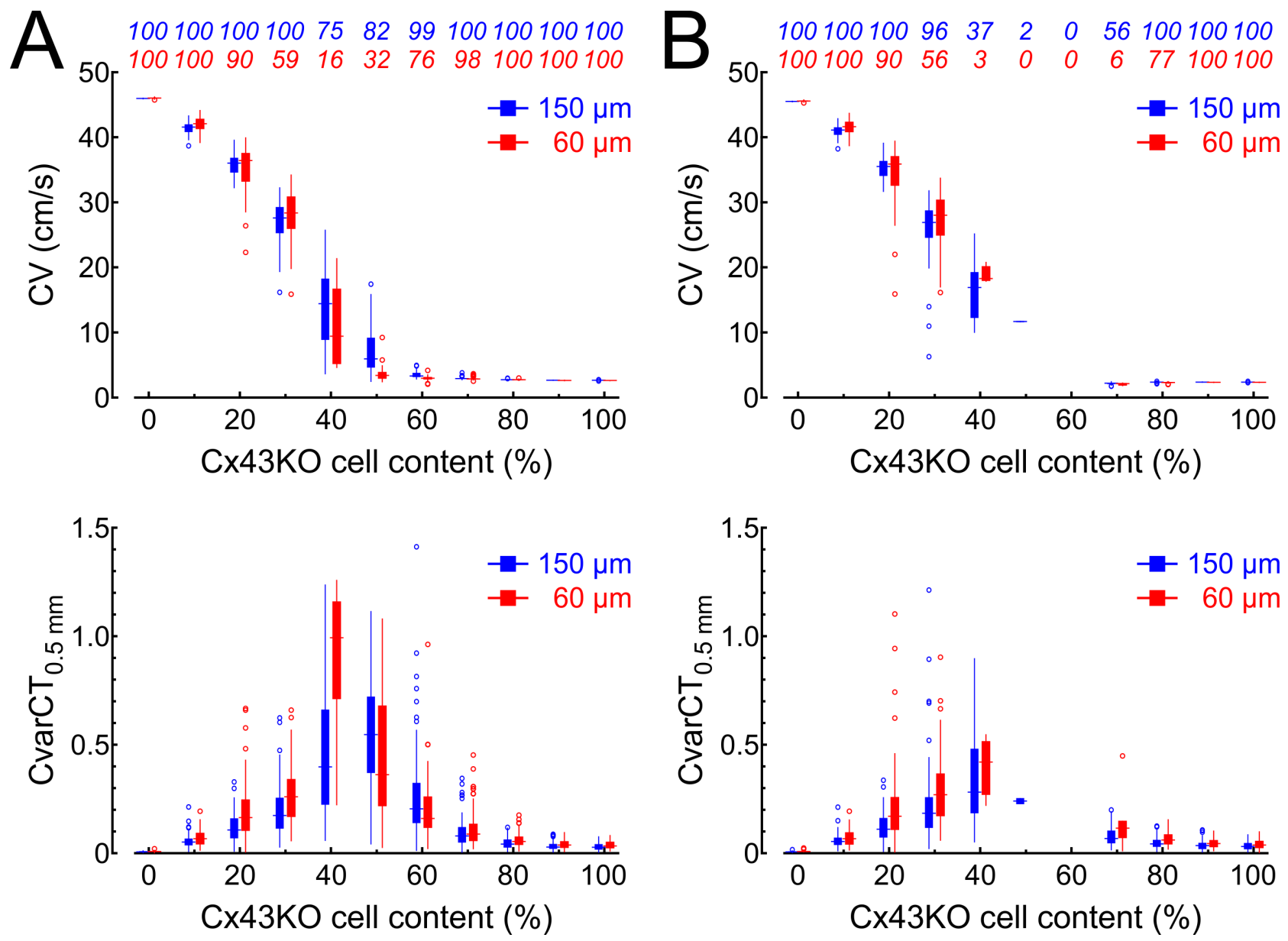

Figure S4. Tukey box plots of $C V$ (top) and CvarCT $_{0.5 \mathrm{~mm}}$ (bottom) in the simulations of conduction in 150 and $60 \mu \mathrm{m}$ wide strands (blue and red, respectively) with detailed cellular structure. (A) LR1 model with enhanced $\mathrm{Ca}^{2+}$ current. (B) Same as A, for the original LR1 model. The numbers above the plots indicate the number of simulations with successful conduction (for which CV and $\mathrm{CvarCT}_{0.5 \mathrm{~mm}}$ could be calculated) out of 100 simulations with different tissue realizations. Data are shown as median (horizontal bars), $1^{\text {st }}$ to $3^{\text {rd }}$ quartile (thick vertical bar), range of data within 1.5 times the interquartle range from both quartiles (whiskers), and data out of this latter range (outliers; circles). 
Tukey box plots of the data (regression slopes of $\log \left(\mathrm{CvarCT}_{\mathrm{d}}\right)$ vs. $\log (d)$ and intercepts with $\mathrm{CVarCT}_{\mathrm{d}}=0$ ) presented in Figure 8 of the main article are shown in Figure S5.

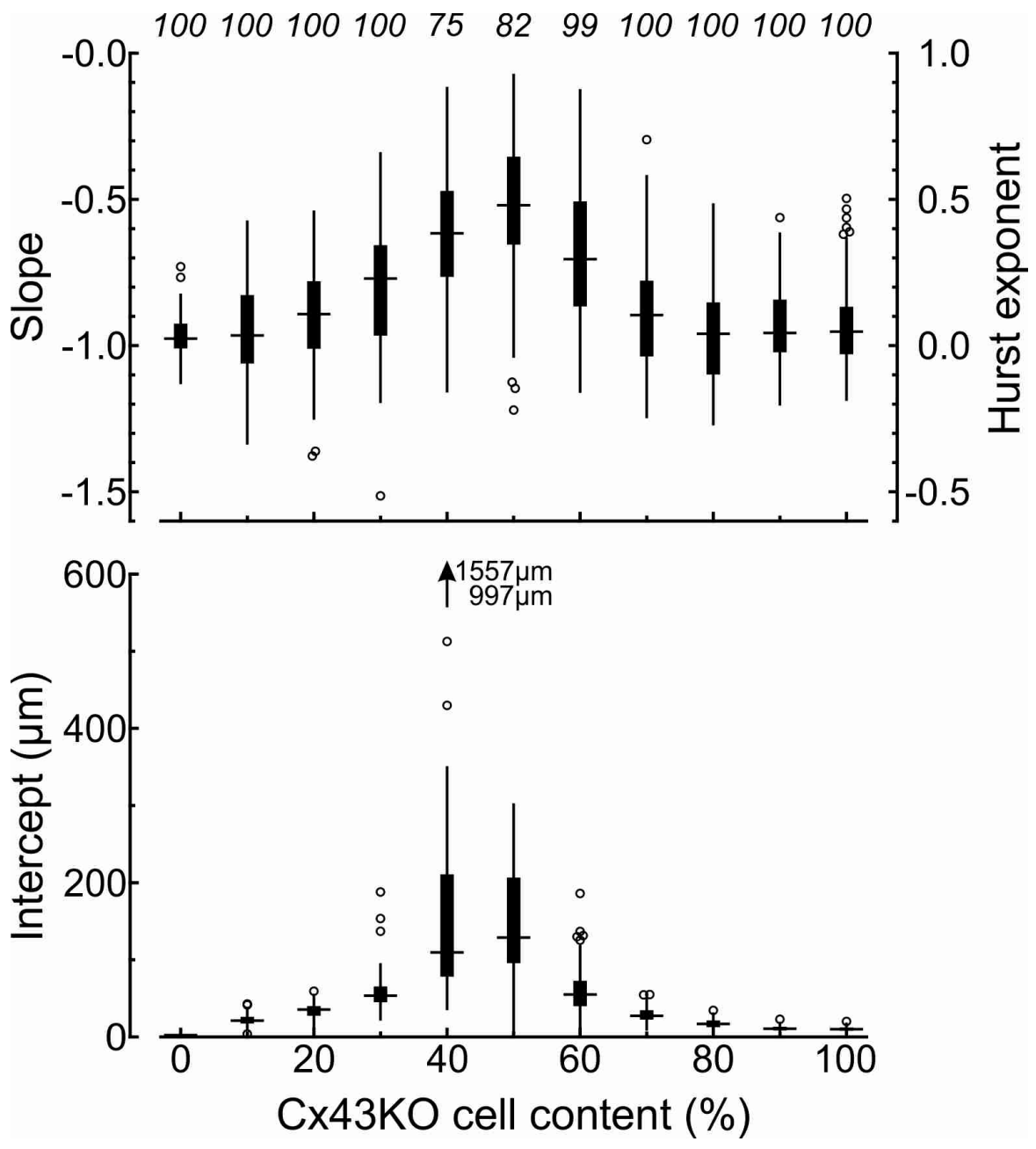

Figure S5. Tukey box plots of the regression slopes of $\log \left(C \operatorname{varCT} T_{d}\right)$ vs. $\log (d) /$ Hurst exponents (top) and of the intercepts with the line $C \operatorname{VarCT}_{d}=0$ (bottom) in the simulations of conduction in 150 $\mu m$ wide strands with detailed cellular structure (LR1 model with enhanced $\mathrm{Ca}^{2+}$ current). The numbers above the plot indicate the number of simulations with successful conduction out of 100 simulations with different tissue realizations. Data are shown as median (horizontal bars), $1^{\text {st }}$ to $3^{\text {rd }}$ quartile (thick vertical bar), range of data within 1.5 times the interquartle range from both quartiles (whiskers), and data out of this latter range (outliers; circles). For the Cx43KO cell content of 40\%, two outliers are located outside the plot area (1557 and $997 \mu \mathrm{m})$. 


\subsection{Conduction characteristics in randomly generated tissues with further paradigms of gap junctional coupling}

Conduction characteristics were evaluated in simulations of propagation in randomly generated tissue strands (width: $150 \mu \mathrm{m}$ ) with further paradigms of gap junctional coupling (see subsection 1.2.3. and Table S1 of this supplementary material). In a first series of simulations, the connexin expression level of each cell was drawn randomly from i) a uniform distribution between 0 (no connexin expression) and 1 (normal WT connexin expression level) and ii) an exponential distribution with a mean of 0.0012. Because the distribution of $\mathrm{Cx} 43$ expression between intercalated discs and lateral membranes is frequently altered during disease [24-26], we also evaluated in a second series of simulations the effect of a complete longitudinal or lateral uncoupling of WT tissue (by setting $\gamma_{\mathrm{L}}$ or $\gamma_{\mathrm{T}}$ (see Table S1) to 0 , respectively).

As reported in Table S2, assigning to each cell a random level of connexin expression drawn from a uniform distribution between 0 and 1 caused only a 22\% decrease of CV. The exponential distribution of a low level of connexin expression (0.0012) caused very slow conduction $(2.5 \%$ of control). Longitudinal uncoupling of WT tissue slowed conduction by $54 \%$, whereas transverse uncoupling slowed longitudinal conduction by $16 \%$. This latter result is similar to the $16 \%$ decrease reported by Hubbard and colleagues [27] for transverse uncoupling.

Interestingly, none of these paradigms resulted in conduction blocks or in manifestly heterogeneous conduction $\left(\mathrm{CvarCT}_{0.5 \mathrm{~mm}}\right.$ remained $<0.2$ and the intercept I remained smaller than cell length). This finding indicates that in strands combining WT and Cx43KO genotypes, conduction heterogeneity and block are due to the bimodal distribution of the level of connexin expression.

Table S2. Conduction characteristics in tissues with further paradigms of gap junctional coupling. $n=100$ tissue realizations for each paradigm.

\begin{tabular}{|l|r|r|r|r|r|}
\hline Paradigm & $\mathbf{C V}(\mathbf{c m} / \mathbf{s})$ & Blocks & CvarCT $_{\mathbf{0 . 5}} \mathbf{~ m m}$ & $\mathbf{H}^{*}$ & $\left.\mathbf{I}_{\mathbf{( \mu m}}\right)^{* *}$ \\
\hline $\begin{array}{l}\text { Control } \\
(100 \% \text { WT cell content) }\end{array}$ & $45.98 \pm 0.07$ & $0 / 100$ & $0.006 \pm 0.003$ & $0.03 \pm 0.07$ & $2.3 \pm 0.7$ \\
\hline $\begin{array}{l}\text { Uniform Cx distribution } \\
\text { between 0 and 1 }\end{array}$ & $36.03 \pm 0.50$ & $0 / 100$ & $0.035 \pm 0.019$ & $0.11 \pm 0.16$ & $10.0 \pm 4.8$ \\
\hline $\begin{array}{l}\text { Exponential Cx distribution } \\
\text { with a mean of 0.0012 }\end{array}$ & $1.13 \pm 0.10$ & $0 / 100$ & $0.139 \pm 0.069$ & $0.33 \pm 0.20$ & $20.8 \pm 10.4$ \\
\hline $\begin{array}{l}\text { Longitudinal uncoupling of } \\
\text { WT tissue }\end{array}$ & $21.20 \pm 1.07$ & $0 / 100$ & $0.080 \pm 0.047$ & $0.22 \pm 0.18$ & $16.7 \pm 7.1$ \\
\hline $\begin{array}{l}\text { Transverse uncoupling of } \\
\text { WT tissue }\end{array}$ & $38.80 \pm 1.27$ & $0 / 100$ & $0.083 \pm 0.054$ & $0.12 \pm 0.19$ & $24.3 \pm 9.1$ \\
\hline
\end{tabular}

* H: Hurst exponent

** I: Intercept of the regression line of $\log \left(\mathrm{CvarCT}_{\mathrm{d}}\right)$ vs. $\log (d)$ at $\mathrm{CvarCT}_{\mathrm{d}}=1$

Cx: connexin 


\section{Video files}

Video 1: Simulation of propagation in the tissue model with $30 \% \mathrm{Cx} 43 \mathrm{KO}$ cells (corresponds to Figure 3).

Video 2: Simulation of propagation in the tissue model with $70 \% \mathrm{Cx} 43 \mathrm{KO}$ cells (corresponds to Figure 4).

Video 3: Simulation of anterograde propagation in the tissue model with $50 \% \mathrm{Cx} 43 \mathrm{KO}$ cells (corresponds to the first activation map in Figure 5).

Video 4: Simulation of retrograde block in the same realization of the tissue model as in Video 3 (50\% Cx43KO cells; the video corresponds to the second activation map in Figure 5).

Video 5: Simulation of propagation in the tissue model with $0 \% \mathrm{Cx} 43 \mathrm{KO}$ cells (corresponds to Figure S2).

Video 6: Simulation of propagation in the tissue model with $100 \% \mathrm{Cx} 43 \mathrm{KO}$ cells (corresponds to Figure S3).

\section{Supplementary references}

[1] Reaume AG, de Sousa PA, Kulkarni S, Langille BL, Zhu D, Davies TC, et al. Cardiac malformation in neonatal mice lacking connexin43. Science 1995;267:1831-4.

[2] Beauchamp P, Choby C, Desplantez T, de Peyer K, Green K, Yamada KA, et al. Electrical propagation in synthetic ventricular myocyte strands from germline connexin 43 knockout mice. Circ Res 2004;95:170-8.

[3] Beauchamp P, Desplantez T, McCain ML, Li W, Asimaki A, Rigoli G, et al. Electrical coupling and propagation in engineered ventricular myocardium with heterogeneous expression of connexin43. Circ Res 2012;110:1445-53.

[4] Rohr S, Flückiger-Labrada R, Kucera JP. Photolithographically defined deposition of attachment factors as a versatile method for patterning the growth of different cell types in culture. Pflugers Arch 2003;446:125-32.

[5] Kondratyev AA, Ponard JG, Munteanu A, Rohr S, Kucera JP. Dynamic changes of cardiac conduction during rapid pacing. Am J Physiol Heart Circ Physiol 2007;292:H1796-H811.

[6] Thomas SP, Bircher-Lehmann L, Thomas SA, Zhuang J, Saffitz JE, Kléber AG. Synthetic strands of neonatal mouse cardiac myocytes: structural and electrophysiological properties. Circ Res 2000;87:467-73.

[7] Thomas SP, Kucera JP, Bircher-Lehmann L, Rudy Y, Saffitz JE, Kléber AG. Impulse propagation in synthetic strands of neonatal cardiac myocytes with genetically reduced levels of connexin43. Circ Res 2003;92:1209-16.

[8] Shaw RM, Rudy Y. Ionic mechanisms of propagation in cardiac tissue. Roles of the sodium and L-type calcium currents during reduced excitability and decreased gap junction coupling. Circ Res 1997;81:727-41.

[9] Hubbard ML, Henriquez CS. Microscopic variations in interstitial and intracellular structure modulate the distribution of conduction delays and block in cardiac tissue with source-load mismatch. Europace 2012;14 Suppl 5:v3-v9.

[10] Kléber AG, Riegger CB. Electrical constants of arterially perfused rabbit papillary muscle. J Physiol 1987;385:307-24. 
[11] Luo CH, Rudy Y. A dynamic model of the cardiac ventricular action potential. I. Simulations of ionic currents and concentration changes. Circ Res 1994;74:1071-96.

[12] Fast VG, Darrow BJ, Saffitz JE, Kléber AG. Anisotropic activation spread in heart cell monolayers assessed by high-resolution optical mapping. Role of tissue discontinuities. Circ Res 1996;79:115-27.

[13] Davis LM, Rodefeld ME, Green K, Beyer EC, Saffitz JE. Gap junction protein phenotypes of the human heart and conduction system. J Cardiovasc Electrophysiol 1995;6:813-22.

[14] Darrow BJ, Laing JG, Lampe PD, Saffitz JE, Beyer EC. Expression of multiple connexins in cultured neonatal rat ventricular myocytes. Circ Res 1995;76:381-7.

[15] McCain ML, Desplantez T, Geisse NA, Rothen-Rutishauser B, Oberer H, Parker KK, et al. Cell-to-cell coupling in engineered pairs of rat ventricular cardiomyocytes: relation between Cx43 immunofluorescence and intercellular electrical conductance. Am J Physiol Heart Circ Physiol 2012;302:H443-50.

[16] Luo CH, Rudy Y. A model of the ventricular cardiac action potential. Depolarization, repolarization, and their interaction. Circ Res 1991;68:1501-26.

[17] Wang LJ, Sobie EA. Mathematical model of the neonatal mouse ventricular action potential. Am J Physiol Heart Circ Physiol 2008;294:H2565-75.

[18] Plonsey R, Barr RC. Bioelectricity, a quantitative approach. New York: Plenum Pub Corp; 1988.

[19] Peitgen HO, Jürgens H, Saupe D. Chaos and Fractals: New Frontiers of Science. New York, NY: Springer-Verlag; 1992.

[20] Di Matteo T, Aste T, Dacorogna MM. Scaling behaviors in differently developed markets. Physica A 2003;324:183-8.

[21] Kucera JP, Rohr S, Rudy Y. Localization of sodium channels in intercalated disks modulates cardiac conduction. Circ Res 2002;91:1176-82.

[22] Tsumoto K, Ashihara T, Haraguchi R, Nakazawa K, Kurachi Y. Roles of subcellular Na+ channel distributions in the mechanism of cardiac conduction. Biophys J 2011;100:554-63.

[23] Krassowska W, Neu JC. Response of a single cell to an external electric field. Biophys J 1994;66:1768-76.

[24] Peters NS, Coromilas J, Severs NJ, Wit AL. Disturbed connexin43 gap junction distribution correlates with the location of reentrant circuits in the epicardial border zone of healing canine infarcts that cause ventricular tachycardia. Circulation 1997;95:988-96.

[25] Cabo C, Yao J, Boyden PA, Chen S, Hussain W, Duffy HS, et al. Heterogeneous gap junction remodeling in reentrant circuits in the epicardial border zone of the healing canine infarct. Cardiovasc Res 2006;72:241-9.

[26] Severs NJ, Bruce AF, Dupont E, Rothery S. Remodelling of gap junctions and connexin expression in diseased myocardium. Cardiovasc Res 2008;80:9-19.

[27] Hubbard ML, Ying W, Henriquez CS. Effect of gap junction distribution on impulse propagation in a monolayer of myocytes: a model study. Europace 2007;9 Suppl 6:vi20-8. 